\title{
Predictors of Caregiving in Adult Intimate Relationships: An Attachment Theoretical Perspective
}

\author{
Brooke C. Feeney \\ State University of New York at Buffalo
}

\author{
Nancy L. Collins \\ University of California, Santa Barbara
}

\begin{abstract}
Romantic couples $(N=194)$ participated in an investigation of caregiving processes in adulthood. In Phase 1, couple members completed questionnaires designed to identify attachment style differences in caregiving behavior and to explore the underlying (personal and relationship) mechanisms that lead people with different attachment styles to be effective or ineffective caregivers. Results revealed that social support knowledge, prosocial orientation, interdependence, trust, and egoistic motivation mediated the link between attachment style and caregiving. In Phase 2, responsive caregiving was assessed behaviorally by exposing one member of the couple to a stressful laboratory situation and experimentally manipulating his or her need for support. Results revealed that attachment style and mediating mechanisms identified in Phase 1 also predicted observable support behavior in a specific episode in which a partner had a clear need for support.
\end{abstract}

Caregiving has been identified as a basic component of human nature and a primary element of close relationships (Weiss, 1980). Indeed, Bowlby (1988) argued that the capacity to make intimate emotional bonds with others, sometimes in the care-seeking role and sometimes in the caregiving role, is a principal feature of effective personality functioning and mental health. It has also been argued that a healthy, well-functioning partnership is possible only when the members are intuitively alive (Bowlby, 1988) to the crucial role they play as caregivers and support providers (Bretherton, 1987).

In adulthood, romantic partners are frequently called on to provide comfort and assistance to one another in times of need, and many adults come to rely heavily on their romantic partner as an important (if not their most important) source of support and care. It is not surprising that research indicates that social support and caregiving are essential not only to personal health and well-being but also to the development and maintenance of healthy and satisfying intimate relationships (e.g., Acitelli, 1996; Carnelley,

Brooke C. Feeney, Department of Psychology, State University of New York at Buffalo; Nancy L. Collins, Department of Psychology, University of California, Santa Barbara.

Funding for this project was provided by a Mark Diamond Dissertation Research Award (State University of New York at Buffalo). Preparation of this article was supported by National Science Foundation Grant SBR9870524. We gratefully acknowledge the contributions of Joe Chason, Elaine Healy, Brent Jones, Kathy Morales, Alex Murray, and Tulin Ture, who assisted with data collection and coding. Special thanks go to Carolyn Cutrona, Paul Luce, Jack Meacham, and Sandra Murray for helpful comments and suggestions on versions of this article.

Correspondence concerning this article should be addressed to Brooke C. Feeney, who is now at the Department of Psychology, University of Maryland, College Park, Maryland 20742, or to Nancy L. Collins, Department of Psychology, University of California, Santa Barbara, California 93106. Electronic mail may be sent to brookefeeney@wam.umd.edu or to ncollins@psych.ucsb.edu.
Pietromonaco, \& Jaffe, 1996; Collins \& Feeney, 2000; Cutrona, 1996; J. A. Feeney, 1996; Julien \& Markman, 1991). However, despite the fact that caregiving is critical for well-being, we know surprisingly little about the caregiving processes that occur in adult close relationships. Most of the existing literature has focused on the experiences of the person who is in need of support, and much less attention has been given to the person providing support.

There are many questions about caregiving that deserve research attention. For example, can we identify individuals who are effective and ineffective caregivers? If so, what are the personal and interpersonal factors that explain these differences? A number of studies suggest that individual differences in adult attachment style may be one important predictor of caregiving behavior in adult close relationships. Thus, the current investigation takes an indepth look at caregiving in adult intimate relationships from an attachment theoretical perspective. Specifically, we examine attachment style differences in caregiving by identifying specific patterns of caregiving behavior and by exploring a number of possible mediators that may explain these differences. We investigate these issues in a large sample of adult romantic couples using both self-report and laboratory methodologies.

\section{Relevance of Attachment Theory to the Study of Caregiving Processes}

Attachment theory provides an ideal framework for studying caregiving processes because it stipulates that the need for security is a fundamental need for adults as well as for children and because it provides the basis for understanding the complex attachmentcaregiving bond.

\section{Attachment}

According to attachment theory, individuals come into the world equipped with an attachment behavioral system that is prone to activation when an individual is distressed, and the goal of this 
system is to maintain a feeling of security (Bowlby, 1973, 1980, 1982). Bowlby postulated that the attachment system serves a major evolutionary function of protection and survival; it is activated most strongly in adversity, so that when frightened, tired, or ill, an individual will seek protection and comfort from a primary caregiver (Bowlby, 1982).

Because not everyone has experienced responsive and reliable caregiving in times of need, not everyone expects to get their attachment needs met. This has led researchers to identify individual differences in attachment styles or patterns (Ainsworth, Blehar, Waters, \& Wall, 1978; Bartholomew \& Horowitz, 1991; Hazan \& Shaver, 1987). Attachment styles can be thought of as chronic interpersonal styles that reflect people's general beliefs about themselves and others-beliefs about whether the self is worthy of care and affection, and beliefs about whether other people are generally dependable and responsive. The different patterns of attachment also represent different strategies of affect regulation, or rules that guide individuals' responses to emotionally distressing situations (Kobak \& Sceery, 1988).

Adult attachment researchers typically define four prototypic attachment styles derived from two underlying dimensions-anxiety and avoidance (e.g., Bartholomew \& Horowitz, 1991; Brennan, Clark, \& Shaver, 1998). The anxiety dimension assesses the degree to which the self is perceived to be worthy or unworthy of love and the degree to which the individual is worried about being rejected by others. Anxious attachment is organized by rules that direct attention toward distress and attachment figures in a hypervigilant manner, which inhibits the development of autonomy and self-confidence. The avoidance dimension assesses the degree to which individuals perceive others to be generally responsive or unresponsive and the degree to which individuals are comfortable with intimacy and dependency on others. Avoidant attachment is organized by rules that restrict acknowledgment of distress as well as any attempts to seek comfort and support from others. The four attachment styles can be conceptualized in terms of these two underlying dimensions as follows: Secure adults are low in both anxiety and avoidance, preoccupied adults are high in anxiety and low in avoidance, fearful avoidant individuals are high in both anxiety and avoidance, and dismissing avoidant individuals are low in anxiety but high in avoidance.

\section{Caregiving}

Attachment theory stipulates that the caregiving system is another normative, safety-regulating system that is intended to reduce the risk of a close other coming to harm. Caregiving has been defined as a broad array of behaviors that complement a partner's attachment behavior and may include a wide range of responsibilities, such as providing help or assistance, offering comfort and reassurance, providing a secure base, and encouraging autonomy (Bowlby, 1982, 1988; Kunce \& Shaver, 1994). Bowlby (1982, 1988 ) identified the need to study the caregiving system within a conceptual framework similar to that adopted for attachment behavior. However, with only a few exceptions (e.g., Carnelley et al., 1996; Collins \& Feeney, 2000; J. A. Feeney, 1996; George \& Solomon, 1996, 1999; Kunce \& Shaver, 1994; Solomon \& George, 1996), the study of caregiving as a behavioral system has received little attention.

\section{Attachment Style Differences in Caregiving}

Because working models of attachment (attachment styles) are built interactionally and encompass views of both self and others (both sides of the attachment-caregiving relationship), beliefs about the likelihood of receiving care from others (and rules that guide support-seeking behavior and the regulation of personal distress) are likely to be linked to beliefs about providing care to others (and rules that guide caregiving behavior and the regulation of a significant other's distress; Collins \& Feeney, 2000; Kunce \& Shaver, 1994). Kunce and Shaver (1994) were the first to identify the links between attachment style and caregiving patterns in adult intimate relationships, and other researchers have shown (in selfreport and observational studies) that attachment style is systematically associated with caregiving. We briefly review these studies below.

\section{Self-Reported Caregiving Behaviors}

In a series of self-report studies, attachment researchers have shown that each attachment style is associated with a unique pattern of caregiving (Carnelley et al., 1996; J. A. Feeney, 1996; Kunce \& Shaver, 1994). Specifically, secure individuals (low anxiety and low avoidance) report relatively high levels of sensitivity and proximity (i.e., physical forms of comfort), coupled with relatively low levels of compulsive (i.e., overinvolved) and controlling caregiving. In contrast, preoccupied individuals (high anxiety and low avoidance) report relatively low levels of sensitivity and cooperation but relatively high levels of proximity and compulsive caregiving-suggesting that their caregiving behaviors may be inconsistent, intrusive, and out of sync with their partner's needs. Dismissing individuals (low anxiety and high avoidance) report the lowest levels of compulsive caregiving and provision of proximity, and they also report relatively low levels of sensitivity. Finally, fearful individuals (high anxiety and high avoidance) report relatively low levels of sensitivity and proximity, while simultaneously reporting relatively high levels of compulsive caregiving.

\section{Observed Caregiving Behaviors}

Although observational research is still relatively rare in the social support literature, several attachment researchers have examined whether self-reported attachment style is predictive of directly observable caregiving behavior. Simpson, Rholes, and Nelligan (1992) observed the spontaneous caregiving behavior offered by male caregivers when a female dating partner was exposed to an anxiety-provoking experimental procedure. Secure men offered more comfort and reassurance, whereas avoidant men were less inclined to offer support (and displayed more anger) as their partners displayed greater anxiety (see also Rholes, Simpson, \& Orina, 1999). However, no significant effects emerged for caregivers who had an anxious attachment style. This pattern of results was corroborated in a field study conducted by Fraley and Shaver (1998), in which they observed couples separating at an airport. In a more recent study in which participants were videotaped as they discussed a current stressful event in their lives with their romantic partners, Collins and Feeney (2000) found that caregivers who were high in anxiety were less responsive during 
the interaction and provided less positive (e.g., emotional and instrumental support) and more negative (e.g., dismissing the problem, blaming the partner) forms of support. In another study, in which romantic couples were unobtrusively videotaped after one member of the couple was asked to give a speech, B. C. Feeney and Collins (1998) found that caregiver avoidance was associated with less responsiveness, less proximity seeking, and less warmth and friendliness. Important links between adult attachment representations and caregiving behaviors have also been shown in several observational studies of mothers and children (Crowell \& Feldman, 1988, 1991; see van IJzendoorn, 1995, for a meta-analytic review). In all of these studies, secure adult attachment was associated with sensitive, warm, and positive maternal caregiving behaviors.

\section{Why Are People With Different Attachment Styles Effective or Ineffective Caregivers?}

On the basis of the studies reviewed above, it appears that individuals with a secure attachment style (low anxiety, low avoidance) tend to be good, responsive caregivers: They are warm, sensitive, and cooperative, and they actively help their partners solve problems. Insecure adults, on the other hand, tend to be relatively poor caregivers, but they exhibit different forms of unresponsive caregiving depending on their particular type of insecurity. It is important to note, however, that the few observational studies that have examined links between attachment style and behavioral measures of caregiving provided to romantic partners to date have yielded somewhat inconsistent results, most likely as a result of differences in the particular laboratory situation or support context. That is, in two studies in which participants were unobtrusively observed in stressful situations, avoidant individuals emerged as particularly poor caregivers (Simpson et al., 1992; B. C. Feeney \& Collins, 1998); however, another study, in which couples discussed a problem identified as stressful to one member of the couple, revealed that anxious individuals were the especially poor and ineffective caregivers (Collins \& Feeney, 2000).

Although researchers have shown that attachment style is systematically associated with caregiving behavior, we currently know little about the specific mediating mechanisms that can explain these differences. Why are people with different attachment styles effective or ineffective caregivers? Discovering the answer to this question is important for several reasons. First, it enables us to gain greater insight into individual differences in attachment style and greater understanding of the interface between the attachment and caregiving systems. Second, it enables us to learn, more broadly, about the particular skills, resources, and motivations that are associated with caregiving in close relationships.

What are the necessary ingredients for caregiving? For one to identify the mediators that explain attachment style differences in caregiving, it is important to consider the factors that are required for effective caregiving. We believe that three major ingredients are necessary for the provision of responsive care and support and that insecure individuals may be relatively poor caregivers because they lack one or more of these necessary ingredients.

First, effective caregiving requires individuals to possess relevant skills and abilities. For example, individuals must be able to respond flexibly to a wide range of needs as they arise, and caregivers must have adequate knowledge about how to provide the appropriate type and amount of support that is needed. Additional skills important for sensitive caregiving include (a) the ability to empathize with and take the perspective of distressed individuals and (b) social skills that assist caregivers in orienting themselves toward others and recognizing their needs.

Second, effective caregiving requires adequate emotional and material resources. In describing the conditions necessary for parents to be sensitive and attentive caregivers, Bowlby (1988) acknowledged that adequate time and a relaxed atmosphere are necessary. These same resources should be necessary for adults to be responsive to one another. For example, if an individual is stressed, overwhelmed with work or family responsibilities, and experiencing time constraints, it is likely that his or her caregiving behavior will suffer because he or she will be self-focused and may temporarily lack the emotional energy and cognitive resources necessary to devote to his or her partner. Because the attachment and caregiving roles are not exclusively assigned to one member of a dyad in adult relationships, adult partners may frequently experience stressful events concurrently, and recent studies suggest that caregiving quality may deteriorate under these circumstances (Vinokur, Price, \& Caplan, 1996; Wood, Saltzberg, \& Goldsamt, 1990). It is important to note that one can lack resources either chronically (e.g., chronic self-focus) or situationally (e.g., situation-specific self-focus).

Finally, an individual must have the motivation to provide care. The caregiving role often involves a good deal of responsibility as well as a substantial amount of cognitive, emotional, and sometimes tangible resources. Therefore, caregivers must be motivated to accept that responsibility (which often involves some degree of sacrifice) and expend the time and effort required to provide effective support. If caregivers are not sufficiently motivated, they may provide either low levels of care or ineffective forms of caregiving that are out of sync with their partner's needs. Motivations for caregiving may be chronic (e.g., a general communal orientation toward others), relationship-specific (e.g., a feeling of commitment to and responsibility for a particular individual), or situation-specific (e.g., feeling pressured or obligated to provide support in a particular situation).

\section{The Current Investigation}

The current investigation focuses explicitly on the caregiver to address two specific research goals. The first goal is to provide further evidence for attachment style differences in caregiving behavior by using self-report and laboratory methods and by exploring a wider variety of caregiving patterns than have been examined in prior research. The second goal is to provide a more detailed understanding of caregiving dynamics by identifying the mediators of these attachment style differences in caregiving. Specifically, we seek to identify the personal and interpersonal factors (on the basis of the ingredients for good caregiving listed above) that may lead people with different attachment styles to be effective or ineffective caregivers. Our interest is both in explaining attachment style differences in caregiving and, more generally, in understanding the predictors of effective caregiving.

We addressed these objectives in a two-phase investigation involving romantic couples. We used a self-report methodology 
during the first phase to identify the factors that predict various forms of caregiving and lead individuals with different attachment styles to be effective or ineffective caregivers. In the second phase of this investigation, we used an experimental-observational methodology to obtain behavioral evidence of caregivers' responsiveness and attentiveness to their partner's needs.

\section{Phase 1 (Questionnaire Session): Hypotheses}

\section{Attachment Style Differences in Patterns of Caregiving}

Before we examine the mediational hypotheses, it is important to replicate and extend the associations between attachment style and caregiving that have been observed in previous studies. Consistent with recent theoretical and empirical advances in the field (Brennan et al., 1998; Fraley \& Waller, 1998), our hypotheses concerning attachment style differences focus on the dimensions of attachment-related anxiety and avoidance. On the basis of theory and previous research, we expected that avoidance would be associated with an unfavorable caregiving style characterized by low levels of responsive caregiving and high levels of controlling caregiving. In contrast, we expected that attachment-related anxiety would be associated with a caregiving style characterized by high levels of both compulsive and controlling caregiving. Because anxiety has been inconsistently associated with unresponsive caregiving in prior studies, this relationship was more difficult to predict. On the one hand, anxious adults are worried about being rejected and unloved by others, and they tend to direct attention toward attachment figures in a hypervigilant manner; therefore, they may respond to their partner's needs with emotional support and physical proximity. However, their fear of abandonment and lack of confidence in the partner's continuing love and commitment may impede their ability to provide responsive support that is in sync with the needs of the partner.

\section{Proposed Mediators of the Link Between Attachment Style and Caregiving Quality}

The second set of hypotheses concerns the identification of the particular types of skills, resources, and motivations that are likely to influence caregiving quality and mediate the link between attachment style and caregiving. We organized these mediators into personal/individual-level factors and relationship-level factors (see Figure 1).

\section{Personal/Individual-Level Factors}

On the basis of the available literature on close relationships as well as the social support and helping literatures, we identified four relatively chronic individual-level factors that may predict caregiving quality and mediate the link between attachment style and caregiving: (a) empathy (an interpersonal skill or ability), (b) social support knowledge (a skill or ability), (c) chronic self-focus (lack of a cognitive resource), and (d) communal and exchange orientation (general interpersonal motivations). First, numerous studies in the helping literature have indicated that under conditions of empathic concern for another, individuals help more frequently in what appears to be an altruistically motivated attempt to improve the other's well-being (e.g., Batson, O'Quin, Fultz, Vanderplas, \& Isen, 1983; Dovidio, Allen, \& Schroeder, 1990). Therefore, we expected that empathic abilities would be associated with more responsive forms of caregiving. Second, knowledge about effective supportive behavior should

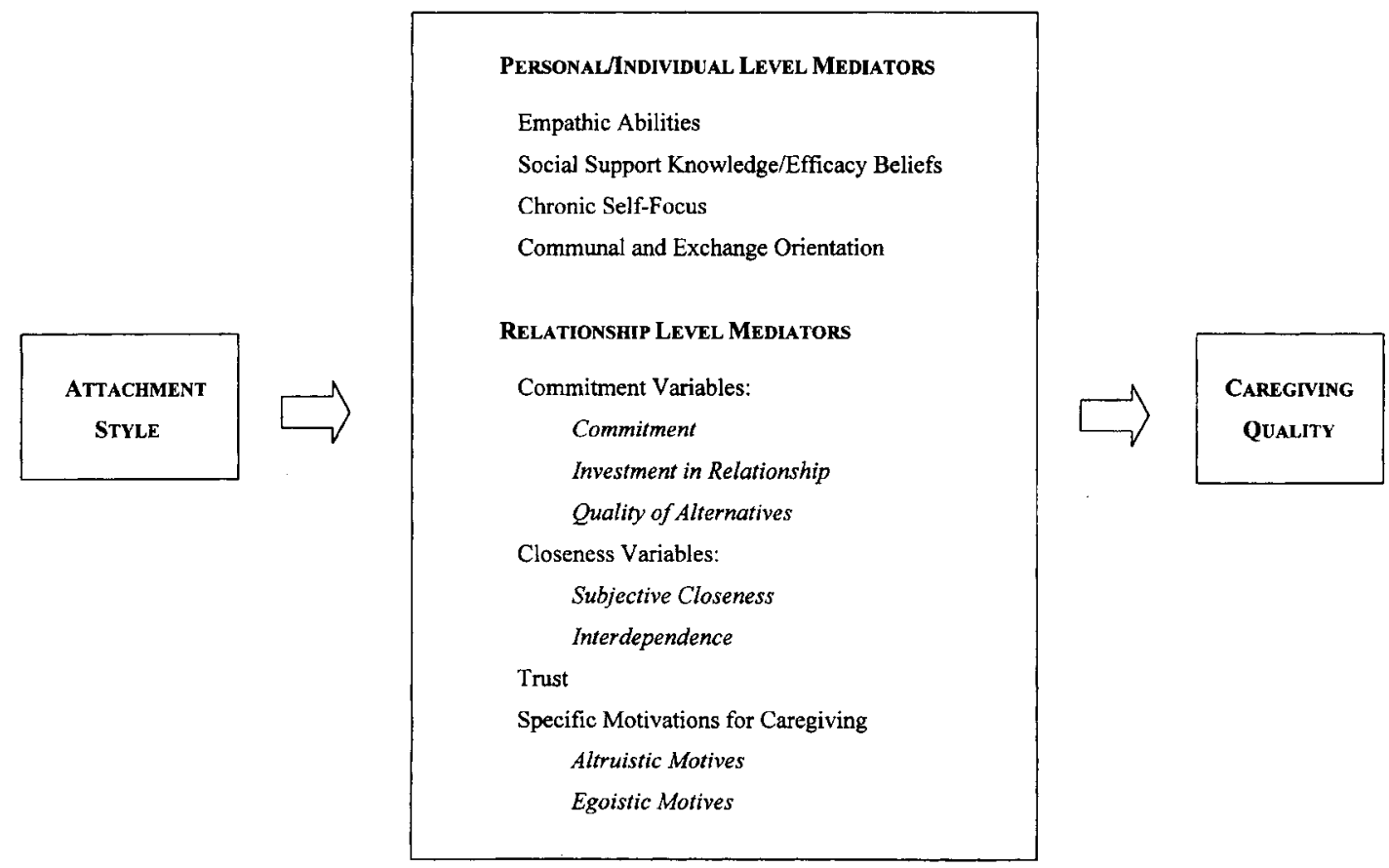

Figure 1. Summary of variables hypothesized to mediate the link between attachment style and caregiving. 
increase the actual support behavior that one romantic partner offers to the other (Johnson, Hobfoll, \& Zalcberg-Linetzy, 1993). Third, because cognitive resources are needed to monitor a partner's needs and to determine how to respond appropriately, chronically selffocused individuals are likely to provide low levels of care (because they fail to notice their partner's needs) or ineffective care that is out of sync with their partner's needs. And finally, because communal and exchange orientation are interpersonal proclivities that involve beliefs about the giving and receiving of benefits (Mills \& Clark, 1994), a communal orientation toward others should be associated with sensitive caregiving, whereas an exchange orientation should be associated with less effective forms of caregiving (Clark, Ouellette, Powell, \& Milberg, 1987).

\section{Relationship-Level Factors}

We also reasoned that four categories of relationship-level factors may predict caregiving quality and mediate the link between attachment style and caregiving: (a) commitment, (b) closeness and interdependence, (c) trust, and (d) altruistic versus egoistic motives for caring for one's partner. We expected all of these relationship factors to function as relationship-specific motivating forces in eliciting caregiving behavior. First, relationship commitment provides individuals with the motivation to engage in pro-relationship behaviors (behaviors that benefit the relationship and help it survive)-even when such behaviors are costly or stand in direct opposition to self-interest (e.g., Rusbult \& Buunk, 1993). We expected that responsive caregiving would be an important pro-relationship behavior. Second, feelings of subjective closeness to one's partner should lead individuals to be willing to give benefits in response to need (e.g., Clark, Mills, \& Powell, 1986; Clark et al., 1987) because the partners' lives have become deeply intertwined and the boundary between self-interest and partner interest is blurred (e.g., Aron, Aron, \& Smollan, 1992). Good caregiving should be observed in close, interdependent relationships because individuals feel responsible for the well-being of their partners and are motivated to improve the joint welfare of the relationship.

Third, because trust involves confidence in a partner's responsiveness to one's needs as well as a willingness to put oneself at risk (Holmes, 1991), individuals who trust their partners should be good caregivers for two reasons: Individuals who are confident that a partner will be responsive to their needs should be more likely to strive to meet their partner's needs, and individuals who are willing to put themselves at risk should be better caregivers because caregiving often involves some risk or cost to oneself. Finally, we reasoned that relationship-specific egoistic and altruistic motivations influence the quality of care (e.g., Batson et al., 1991; Cialdini, Schaller, Houlihan, Arps, Fultz, \& Beaman, 1987). Individuals who are egoistically motivated to care for their partners (to receive rewards or avoid negative consequences) may be poor caregivers because they provide the type of support that is more beneficial to themselves than to the partner. In contrast, individuals who are relatively altruistically motivated (out of genuine concem for the partner's well-being) may be good caregivers because they provide support that is dictated by the partner's needs.

\section{Mediation Hypotheses}

On the basis of the attachment literature and the expected patterns of caregiving, we proposed the following mediational hypotheses. According to the attachment literature, avoidant individuals tend to direct their attention away from attachment needs, emphasize independence and self-reliance, and tend to be involved in relationships characterized by low levels of commitment, interdependence, and trust (Bartholomew \& Horowitz, 1991; Collins \& Read, 1990; J. A. Feeney \& Noller, 1990; Hazan \& Shaver, 1987; Kobak \& Sceery, 1988; Simpson, 1990). Therefore, we expected avoidant individuals to be unresponsive and controlling caregivers because of their low levels of empathy, communal orientation, support knowledge, commitment, relationship closeness, trust, and altruistic caregiving motivation. We also expected avoidant individuals to be unresponsive and controlling caregivers because of their high levels of self-focus, exchange orientation, and egoistic caregiving motivation.

The attachment literature indicates that anxious individuals fear being abandoned and unloved, tend to be dependent on others' acceptance of them for a sense of personal well-being, direct attention toward attachment figures in a hypervigilant manner, and express distrusting views of others (Bartholomew \& Horowitz, 1991; Collins \& Read, 1990; J. A. Feeney \& Noller, 1990; Hazan \& Shaver, 1987; Kobak \& Sceery, 1988; Simpson, 1990). Therefore, we expected anxious individuals to be relatively compulsive and controlling caregivers and perhaps also unresponsive because of their low levels of trust and altruistic caregiving motivation and their high levels of self-focus, exchange orientation, and egoistic caregiving motivation. It is also possible that the high levels of relationship commitment and subjective closeness (characteristic of anxious individuals) may contribute to the link between anxiety and compulsive caregiving.

\section{Method}

\section{Overview}

In this phase of the project, we used questionnaire methodology to assess three sets of factors necessary for testing the hypotheses outlined above: (a) individual differences in the dimensions of attachment style (avoidance and anxiety), (b) a variety of personal- and relationship-level mediator variables, and (c) several comprehensive assessments of caregiving.

\section{Participants}

Participants were 202 couples from the State University of New York at Buffalo and the University of California, Santa Barbara. One member of each couple was recruited from the introductory psychology participant pool and was asked to bring his or her romantic partner to the study. For each phase of this study, the recruited introductory psychology student was designated as the "support recipient," and his or her romantic partner was designated as the "caregiver." The participant of interest was the person in the role of caregiver. The mean age of support recipients was 19.1 (range = $17-33$ ), and the mean age of caregivers was 19.5 (range $=17-28$ ). Couples

1 For purposes of this investigation, it was necessary to focus on one member of each couple as a caregiver and on the other member as a support recipient. This assignment of roles was dictated by Phase 2 of the project. To ensure the validity of responses from all participants during Phase 2 , it was important that the undergraduate psychology participant be designated as the support recipient (the person who would receive the stress induction in Phase 2) and that his or her partner be designated as the caregiver (the person who would not undergo the stress induction). Because romantic partners often participate in our studies as a favor to the undergraduate psychology participants, there was a danger that the validity of the observed caregiving behaviors in Phase 2 would be compromised if the roles 
had been romantically involved for an average of 14.4 months (range $=$ 1-95), and all were heterosexual. The majority of couples were involved in dating relationships $(93 \%)$, and a small percentage were either married or engaged to be married ( $7 \%$ ).

Couple members either received course credit for their participation or were paid $\$ 10$ and offered an opportunity to win a $\$ 100$ prize in a drawing. of the 202 original couples, 8 couples were excluded from data analyses, either because they were not proficient in English or because their involvement in an established romantic relationship was questionable. Of the remaining 194 couples, 111 men and 83 women were assigned to the caregiver role. In analyses involving the attachment dimensions, 2 additional couples were excluded because they did not complete the attachment measures.

\section{Procedure}

Couples were informed that they would be participating in a two-part investigation that was designed to help researchers learn more about the ways people think, feel, and behave in their relationships with their romantic partners. During Phase 1, couple members completed questionnaires in separate, private rooms. An appointment for Phase 2 was then scheduled for approximately 1 week later. The measures used in Phase 1 are described below.

\section{Measures}

Couples completed two attachment measures. First, they completed Brennan et al.'s (1998) 36-item attachment scale, which contains two subscales: The Avoidance subscale $(\alpha=.92)$ measures the extent to which a person is comfortable with closeness and intimacy as well as the degree to which a person feels that people can be relied on to be available when needed. The Anxiety subscale $(\alpha=.92)$ measures the extent to which a person is worried about being rejected, abandoned, or unloved. Couples responded to each item on a scale ranging from 1 (strongly disagree) to 5 (strongly agree) in terms of their general orientation toward close relationships. Next, couples were presented with Bartholomew and Horowitz's (1991) four attachment prototypes (secure, fearful, preoccupied, dismissing) and were asked to rate the extent to which each one corresponded to their general style in romantic relationships. We computed an avoidance dimension by subtracting the secure and preoccupied ratings from the sum of the dismissing and fearful ratings, and we computed an anxiety dimension by subtracting the secure and dismissing ratings from the sum of the preoccupied and fearful ratings.

To achieve the most valid and reliable assessment of attachment style, we combined these measures to form two composite attachment dimensions. The two avoidance indices were highly correlated $(r=.67, p<$ $.001)$ and were combined to form a composite avoidance dimension. High scores on this dimension reflect discomfort with closeness and a tendency to avoid intimate relationships. Likewise, the two anxiety indices were highly correlated $(r=.64, p<.001)$ and were combined to create a composite anxiety dimension. High scores reflect a sense of low self-worth and anxiety about being rejected by others. The avoidance and anxiety composites were not significantly correlated with each other $(r=.08, n s)$.

\section{Personal/Individual-Level Mediating Variables}

Empathy and perspective taking. To obtain the most valid and reliable assessment of dispositional empathy, we had couples complete a 20 -item

were reversed (i.e., if the person who was participating as a favor to his or her partner received the stress induction). However, if both members of the couple were recruited from the undergraduate participant pool, then they were either randomly assigned to roles or assigned on the basis of their attachment characteristics (to ensure an appropriate number of insecure individuals in the caregiving role). measure derived from two widely used empathy scales: the Empathic Concern and Perspective-Taking subscales of the Interpersonal Reactivity Inventory (Davis, 1983), and a measure of emotional empathy (Eysenck \& Eysenck, 1978) that has been referred to as a measure of emotional response matching (Thornton \& Thornton, 1995). The composite empathy index ( $\alpha=.77$ ) assessed the degree to which the respondent is concerned about others, is able to take the perspective of others, and becomes emotionally involved with others' distress (e.g., "I tend to feel nervous when others around me seem to be nervous"). Each item was rated on a scale from 1 (does not describe me well) to 5 (describes me very well).

Social support knowledge and efficacy beliefs. Couples completed a 12-item measure of social support knowledge and efficacy beliefs ( $\alpha=$ .89 ), which was specifically designed for use in this study. This measure assessed the degree to which respondents feel that they know how to help others who are in need of support (e.g., "I'm usually pretty good at knowing how to help people who are feeling distressed about something"). Couples rated each item on a scale from 1 (disagree strongly) to 5 (agree strongly).

Chronic self-focus. Couples completed a six-item measure of chronic self-focus ( $\alpha=.66$ ), which was designed specifically for this study to measure an individual's disposition to be self-centered (e.g., "In my conversations with others, I tend to talk about myself a lot"). Couples rated each item on a scale from 1 (does not describe me at all) to 5 (describes me very well).

Communal and exchange orientation. Couples completed the Communal and Exchange Orientation Scales (Clark et al., 1987; Mills \& Clark, 1994). The Communal Orientation $(\alpha=79)$ Scale includes 14 items that assess the degree to which the respondent behaves in a communal fashion toward others and expects others to do the same (e.g., "When making a decision, I take other people's needs and feelings into account"). The Exchange Orientation ( $\alpha=.65$ ) Scale includes 9 items that assess the degree to which the respondent behaves in an exchange fashion toward others and expects others to do the same (e.g., "When someone buys me a gift, I try to buy that person as comparable a gift as possible"). Couples rated each statement on a scale from 1 (disagree strongly) to 5 (agree strongly).

\section{Relationship-Level Mediating Variables}

Commitment. Couples completed the measure of commitment used by Van Lange et al. (1997), which was modeled after measures used in prior research (Rusbult, 1983) and includes three components: (a) commitment level (e.g., "Do you feel committed to maintaining your relationship with your partner?"), (b) investment size (e.g., "Have you put things into your relationship that you would in some sense lose if the relationship were to end?"), and (c) quality of alternatives (e.g., "How attractive are the people other than your current partner with whom you could become involved?") Each item was rated on a 9-point scale with appropriate anchors. We computed a commitment index by standardizing and averaging the items from the three commitment components $(\alpha=.85)$.

Relationship closeness. Couples completed two measures of relationship closeness. First, the Inclusion of Other in the Self Scale (Aron et al., 1992 ) is a single-item pictorial measure intended to assess one's subjective sense of interconnectedness with a romantic partner. Second, a modified 10 -item version of the Relationship Closeness Inventory's Strength subscale ( $\alpha=.79$; Berscheid, Snyder, \& Omoto, 1989) assessed closeness as a high level of interdependence between partners' activities (e.g., "My partner influences how I spend my free time"). Items were rated on a 7-point scale with appropriate anchors. We computed a composite closeness index ( $\alpha=.80$ ) by standardizing and averaging the two scales.

Trust. Couples completed a modified 18-item version of Rempel, Holmes, and Zanna's (1985) Trust Scale $(\alpha=.92)$, which assesses the respondent's confidence in his or her partner in the face of risk and potential hurt and the respondent's confidence in the degree of caring and responsiveness expected from the partner in the face of an uncertain future 
(e.g., "Though times may change and the future is uncertain, I know my partner will always be there for me"). Participants rated each item on a scale from 1 (strongly disagree) to 7 (strongly agree).

Motivations for caregiving. Couples completed a measure of relationship-specific motivations for caring that was designed specifically for use in this study. Participants were presented with the phrase "On occasions when I help my partner, I generally do so because ..." and were then asked to rate a series of motivations on a scale from 1 (strongly disagree) to 6 (strongly agree). This measure consisted of two subscales: (a) Altruistic/Unselfish Motivations (e.g., "I love my partner and am concerned about my partner's well-being"; 16 items; $\alpha=.84$ ) and (b) Egoistic/Selfish Motivations (e.g., "I want to reduce my own anxiety and escape a distressing situation"; 19 items; $\alpha=.89$ ).

\section{Caregiving Variables}

Couple members completed a variety of caregiving measures designed to assess their own and their partner's caregiving behavior. For purposes of the current investigation, the caregiver's reports of his or her own caregiving behavior were of primary interest.

Caregiving patterns. Respondents completed an abbreviated (24item) version of the Caregiving Questionnaire (Kunce \& Shaver; 1994), which measures four aspects of caregiving. The Proximity subscale ( $\alpha=.74$ ) assessed the degree to which caregivers make themselves physically available to their partner when comfort is needed (e.g., "When my partner seems to want or need a hug, I'm glad to provide it"). The Sensitivity subscale $(\alpha=.79$ ) assessed the degree to which caregivers are able to recognize when their partner needs comfort and support (e.g., "I can always tell when my partner needs comforting, even when s/he doesn't ask for it"). The Controlling subscale $(\alpha=.81)$ measured the degree to which caregivers are controlling in their attempts to help their partners solve problems (e.g., "I tend to be too domineering when trying to help my partner"). Finally, the Compulsive subscale $(\alpha=.59)$ measured the extent to which caregivers get overinvolved in their partner's problems (e.g., "I sometimes create problems by taking on my partner's troubles as if they were my own"). Another series of 6-item scales (written specifically for this study) assessed four additional forms of caregiving: (a) neglect (e.g., "I try not to get involved in my partner's problems"; $\alpha=.87$ ), (b) negative caregiving (e.g., "I sometimes lose patience with my partner when he/she is stressed about something"; $\alpha=.87$ ), (c) instrumental support (e.g., "When my partner needs help with a task, I try to offer to do something to help"; $\alpha=.85$ ), and emotional support (e.g., "When my partner is having a problem, I try to provide reassurance that everything will be okay"; $\alpha=.84$ ).

Caregiving quality. Respondents completed a measure of global caregiving quality ( $\alpha=.86$ ), which provided an overall index of the degree to which they perceived themselves to be a good caregiver. Six items were taken from the Quality of Relationships Inventory (Pierce, Sarason, \& Sarason, 1991) and were reworded to reflect the giving of care to one's partner (e.g." "To what extent can your partner count on you for help with a problem?"). Four additional items were added for use in this study to ensure a reliable measure of the degree to which a caregiver generally provides quality caregiving to his or her partner (e.g., "Overail, I take good care of my partner"). Each item was rated on a scale from 1 (not at allnever) to 5 (very much/very often).

\section{Results and Discussion}

\section{Overview of Hypothesis Testing}

Hypothesis testing was organized around the three central concerns of the study: (a) to identify attachment style differences in caregiving patterns, (b) to examine associations between attach- ment style and the proposed mediators as well as associations among the mediators and the caregiving outcomes, and (c) to identify the mediators of the link between attachment style and caregiving. Hypotheses were tested using the caregiver's report of his or her own behavior.

\section{Preliminary Analyses}

We conducted preliminary analyses to reduce the number of variables wherever possible. First, a principal components analysis confirmed that the nine caregiving scales formed three distinct dimensions. The first factor reflected responsive caregiving and was defined by seven of the nine scales. Thus, we computed a composite index of responsive caregiving by standardizing and averaging proximity, sensitivity, instrumental support, emotional support, negative caregiving (reverse coded), neglect (reverse coded), and global caregiving quality. The reliability estimate of this composite was .96 (see Nunally \& Bernstein, 1994, for information regarding reliabilities of linear composites). The compulsive caregiving and controlling caregiving scales loaded on separate factors (and are conceptually distinct); we therefore retained them as separate caregiving outcomes.

Second, because highly correlated variables pose problems for multivariate data analysis, it was important that the mediating constructs be as independent as possible. Although all of the hypothesized mediators were conceptually distinct, high intercorrelations among some of the variables indicated that they were not empirically distinct. Specifically, we observed high correlations between empathy and communal orientation $(r=.60, p<.001)$, closeness and commitment $(r=.64, p<.001)$, and closeness and relationship-specific altruistic motivation $(r=.65, p<.001)$. On the basis of these correlations and a conceptual analysis of the constructs, we created two composite indices: (a) Empathy and communal orientation were combined into a prosocial orientation index, and (b) closeness, commitment, and altruistic motivations were combined into an interdependence composite. The reliabilities for these composites are .86 and .91 , respectively.

\section{Attachment Style Predicting Caregiving}

The first set of analyses examined associations between attachment style and caregiving patterns (see Table 1). As we predicted, caregivers who were higher in avoidance were less responsive and more controlling in their caregiving style, whereas those who were higher in anxiety were more compulsive and more controlling.

Taken together, these findings indicate that insecure attachment (high avoidance and/or anxiety) was associated with less effective caregiving but that the particular form of ineffective caregiving depended on the particular type of insecurity. Attachment-related avoidance was associated with unresponsive and controlling forms of caregiving, whereas attachment-related anxiety was associated with compulsive (over-involved) and controlling caregiving. ${ }^{2}$

\footnotetext{
2 To validate the caregivers' self-reports of their caregiving behavior, we also examined the support recipient's report of the caregiver's caregiving. As we expected, there was good (but not perfect) agreement between caregivers' and support recipients' reports of the caregivers' behavior (for responsive, $r=.32, p<.001$; for compulsive, $r=.28, p<.001$; and for
} 
Table 1

Correlations Between Attachment Variables and Caregiving Dimensions and Potential Mediators

\begin{tabular}{lcc}
\hline \multicolumn{1}{c}{ Variable } & Avoidance & Anxiety \\
\hline Caregiving variable & & \\
Responsive & $-.46^{* * *}$ & .00 \\
Compulsive & .01 & $.37^{* * *}$ \\
$\quad$ Controlling & $.17^{*}$ & $.19^{* *}$ \\
Personal-level mediator & .04 & $.27^{* * *}$ \\
$\quad$ Self-focus & $-.17^{*}$ & -.02 \\
Support knowledge & $-.37^{* * * *}$ & .10 \\
Prosocial orientation & $.18^{*}$ & $.14 \%$ \\
Exchange orientation & $-.47^{* * *}$ & $.16^{*}$ \\
Relationship-level mediator & $-.33^{* * * *}$ & $-.44^{* * *}$ \\
$\quad$ Interdependence & .11 & $.31^{* * *}$ \\
Trust & & \\
Egoistic motivation & & \\
\hline
\end{tabular}

Note. $N=192$

$\dagger p<.10$ (marginally significant). $* p<.05 . \quad * * p<.01 . \quad * * * p<$ .001 .

\section{Attachment Style Predicting Potential Mediators}

The next set of analyses examined associations between attachment style and the proposed mediators (see Table 1). Consistent with hypotheses, caregivers who were higher in avoidance were less prosocially oriented, were more exchange oriented, and possessed less support knowledge. They also reported lower levels of relationship interdependence and trust. Contrary to our expectations, avoidance was not associated with self-focus or egoistic motivations for providing support.

Consistent with our hypotheses, caregivers who were higher in anxiety were more self-focused and more exchange oriented, although this latter finding was marginally significant and, thus, weaker than we expected. Caregivers who were higher in anxiety also reported greater relationship interdependence, lower levels of relationship trust, and more egoistic motives for helping their partner. Contrary to our expectations, anxiety was not associated with support knowledge or prosocial orientation.

\section{Potential Mediators Predicting Caregiving}

The next set of analyses focused on associations between the mediators and the caregiving outcomes. As shown in Table 2, the variables identified as possible mediators were associated with the caregiving outcomes in theoretically expected ways.

Person-level mediators. Support knowledge and prosocial orientation were associated with more responsive and less controlling

controlling, $r=.28, p<.001$ ). In addition, the overall pattern of correlations between the caregiver's attachment style and the support recipient's report of the caregiver's behavior was similar to that presented in Table 1 using the caregiver's report (for avoidance and responsive, $r=-.28, p<$ .001 ; for anxiety and compulsive, $r=.26, p<.001$; and for anxiety and controlling, $r=.13, p<.10$ ). Thus, the support recipients' reports appear to validate and provide converging evidence for caregivers' claims regarding their own caregiving behavior. This agreement between two different individuals reporting on the same behavior allows us to place greater confidence in the reliability and validity of the self-report data. caregiving. In contrast, an exchange orientation toward others was associated with less responsive and more controlling forms of caregiving. Although we expected self-focus to have moderate associations with all of the caregiving outcomes, it was only weakly associated with compulsive and controlling caregiving.

Relationship-level mediators. Relationship interdependence was associated with more responsive and more compulsive forms of caregiving but was not associated with controlling caregiving. Relationship trust was associated with more responsive, less compulsive, and less controlling forms of caregiving. Finally, egoistic motivation was associated with less responsive caregiving and more compulsive and controlling caregiving.

\section{Mediational Analyses}

In the final series of analyses, we conducted mediational analyses with structural equation modeling (SEM) using AMOS software (Arbuckle, 1997) and maximum-likelihood estimation. We used SEM so that multiple mediating variables and multiple dependent measures could be predicted simultaneously. The conceptual logic involved in the use of SEM to test a complex mediational model is identical to the logic described by Baron and Kenny (1986) using a traditional regression approach.

Specifying the model. In keeping with the criteria necessary for mediation, we made a few small modifications to our hypothesized model on the basis of the previous analyses. That is, some of the hypothesized links between attachment style and the potential mediating variables and between the mediating variables and the caregiving outcomes were not supported in the previous analyses and were therefore excluded from the model.

The mediational model was specified as follows: The two attachment dimensions (avoidance and anxiety) were exogenous variables, the seven person-level and relationship-level factors (self-focus, support knowledge, prosocial orientation, exchange orientation, interdependence, trust, and egoistic motivation) were the mediating variables, and the three caregiving composites (responsive, compulsive, and controlling) were the outcome variables. Guided by hypotheses, we estimated paths from (a) avoidance to support knowledge, prosocial orientation, exchange orientation, interdependence, and trust; (b) anxiety to self-focus, exchange orientation, interdependence, trust, and egoistic motivation; (c) self-focus to compulsive and controlling caregiving; (d) support knowledge to responsive and controlling caregiving; (e) prosocial orientation to responsive and controlling caregiving; (f) exchange orientation to responsive and controlling caregiving; (g) interdependence to responsive and compulsive caregiving; $(\mathrm{h})$ trust to responsive, compulsive, and controlling caregiving; and (i) egoistic motivation to responsive, compulsive, and controlling caregiving. A number of covariances among the residual terms of the mediating variables were also included in the model.

Estimating the model. We evaluated the fit of the model by a joint consideration of the chi-square statistic, the comparative fit index (CFI), the Bentler-Bonett nonnormed fit index (NNFI, also known as the Tucker-Lewis index), and the standardized root mean squared residual (SRMR; Bentler, 1990; Kline, 1998). The chi-square statistic tests whether the hypothesized model adequately explains the observed data, and a nonsignificant chi-square provides evidence of good model fit. The CFI reflects how much better the hypothesized model fits the data relative to a null model, 
Table 2

Correlations Between Potential Mediators and Caregiving Variables

\begin{tabular}{|c|c|c|c|c|c|c|c|}
\hline Caregiving variable & Self-focus & $\begin{array}{c}\text { Support } \\
\text { knowledge }\end{array}$ & $\begin{array}{c}\text { Prosocial } \\
\text { orientation }\end{array}$ & $\begin{array}{l}\text { Exchange } \\
\text { orientation }\end{array}$ & Interdependence & Trust & $\begin{array}{c}\text { Egoistic } \\
\text { motivation }\end{array}$ \\
\hline Responsive & -.06 & $.50^{* * *}$ & $.55^{* * *}$ & $-.25 * * *$ & $.57 * * *$ & $.42 * * *$ & $-.27 * * *$ \\
\hline Compulsive & $.15^{*}$ & .09 & .04 & .04 & $.20^{* *}$ & $-.29 * * *$ & $.32 * * *$ \\
\hline Controlling & $.17^{*}$ & $-.14^{*}$ & $-.30 * * *$ & $.18^{*}$ & -.09 & $-.36 * * *$ & $.32 * * *$ \\
\hline
\end{tabular}

Note. $N=194$.

$* p<.05 . * * *<<.01 . * * * p<.001$.

and the NNFI provides a correction for model complexity. The CFI and NNFI range from 0.0 to 1.0 , with higher scores reflecting better model fit. Values of .95 or greater are desirable for the CFI (Hu \& Bentler, 1999), and values of .90 or greater are desirable for the NNFI (Kline, 1998). The SRMR reflects the average standardized residual, and values of less than 10 are desirable.

The goodness-of-fit statistics indicate that our model provided a good fit to the data, CFI $=.99, \mathrm{NNFI}=.96, \mathrm{SRMR}=.05, \chi^{2}(19$, $N=192$ ) $=27.23, p<.10$. This model appears in Figure 2 (for ease of interpretation, nonsignificant paths are not shown). Consistent with hypotheses, the model indicates that (a) a lack of support knowledge, prosocial orientation, and interdependence mediated the link between avoidance and unresponsive caregiving; (b) a lack of prosocial orientation and trust mediated the link between avoidance and controlling caregiving; (c) higher levels of interdependence, egoistic motivation, and a lack of trust mediated the link between anxiety and compulsive caregiving; and (d) higher levels of egoistic motivation and a lack of trust mediated the link between anxiety and controlling caregiving.

Addition of direct effects to the model. Although the fully mediated model provided a good fit to the data, it was important to estimate the model again, adding direct effects from the attachment variables to the caregiving variables (one at a time) to determine whether model fit would be significantly improved with the direct paths included. First, we added a direct path from avoidance to responsive caregiving. Model fit was significantly improved, $\Delta \chi^{2}(1, N=192)=4.09, p<.05, \mathrm{CFI}=.99$, NNFI $=.97$, SRMR $=.04$, and the direct effect from avoidance to responsive caregiving was statistically significant. However, the direct effect obtained in this model $(\beta=-.10, p<.05)$ was substantially smaller than the total effect shown in Table $1(r=-.46, p<.001)$.

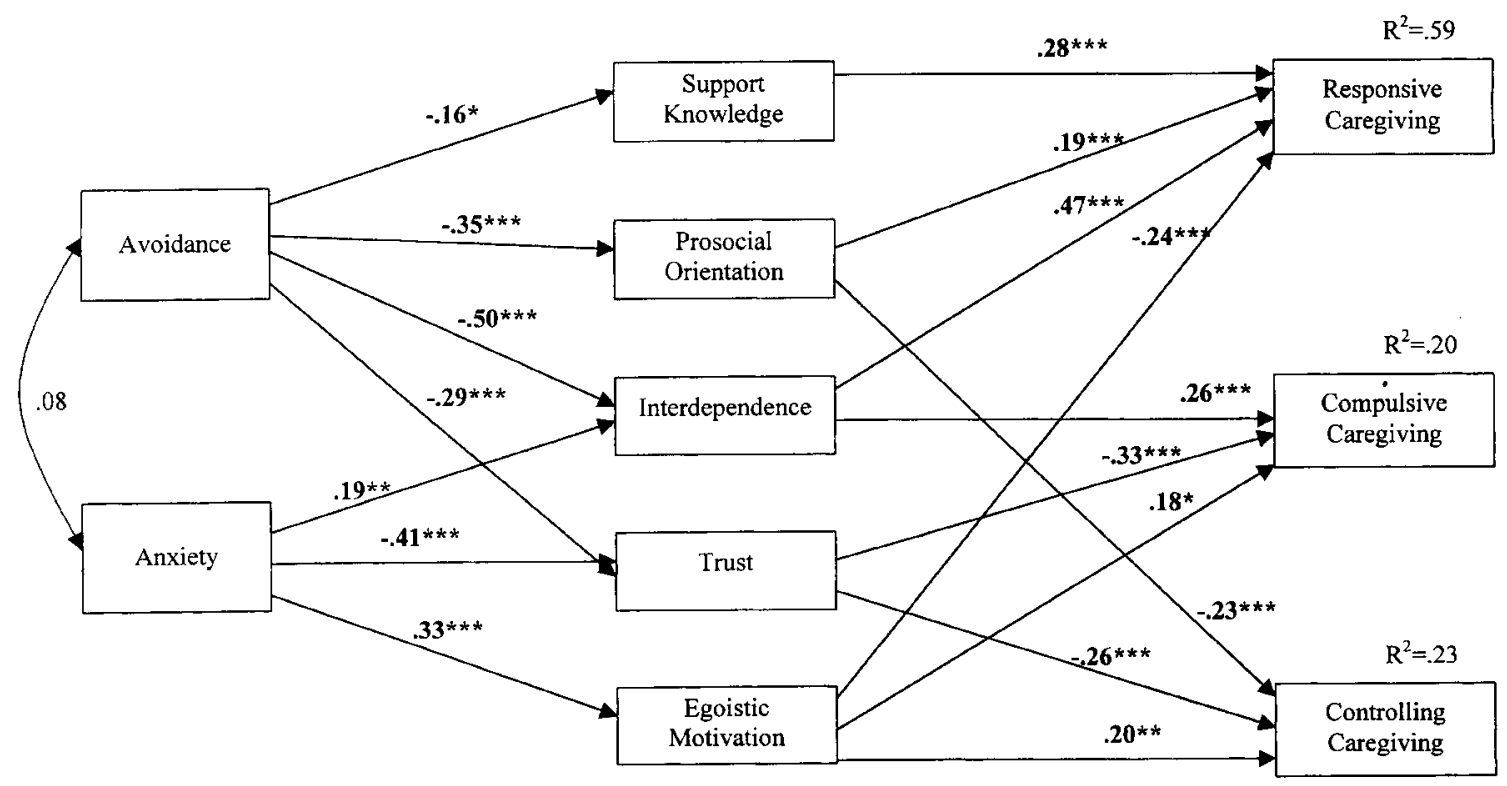

Figure 2. Mediational model. $N=192$. Path values represent standardized regression coefficients. Although both attachment dimensions were significant predictors of exchange orientation $(\beta s=.15, p<.05)$, and although anxiety was a significant predictor of self-focus $(\beta=.29, p<.001)$, exchange orientation and self-focus are not depicted in the above model because they were not significant predictors of any of the caregiving outcomes with the other mediators in the model. ${ }^{*} p<.05 .{ }^{*} p<.01 .{ }^{*} *{ }^{*} p<.001$. 
Thus, support knowledge, prosocial orientation, and interdependence partially yet almost completely mediated the link between avoidance and responsive caregiving. ${ }^{3}$

Next, we added a direct path from anxiety to compulsive caregiving. Again, model fit was significantly improved, $\Delta \chi^{2}(1, N=$ $192)=6.49, p<.05 ; \mathrm{CFI}=1.00, \mathrm{NNFI}=.99, \mathrm{SRMR}=.03$, and the path from anxiety to compulsive caregiving was statistically significant. However, the direct effect obtained in this model $(\beta=$ $.17, p<.01$ ) was substantially smaller than the total effect shown in Table $1(r=.37, p<.001)$. Thus, interdependence, trust, and egoistic motivation partially mediated the link between anxiety and compulsive caregiving.

Next, we added a path from avoidance to controlling caregiving. Model fit was not significantly improved, $\Delta \chi^{2}(1, N=$ $192)=1.55$, ns; CFI $=.99, \mathrm{NNFI}=.96, \mathrm{SRMR}=.05 . \mathrm{In}$ addition, the direct effect from avoidance to controlling caregiving was not significant and was smaller $(\beta=-.07, n s)$ than the total effect shown in Table $1(r=.17, p<.05)$. Thus, a lack of prosocial orientation and trust fully mediated the link between avoidance and controlling caregiving.

Finally, we added a path from anxiety to controlling caregiving. Again, model fit was not significantly improved, $\Delta \chi^{2}(1, N=$ $192)=.15, n s ; \mathrm{CFI}=.99, \mathrm{NNFI}=.95, \mathrm{SRMR}=.05$. In addition, the direct effect from anxiety to controlling caregiving in this model was substantially smaller $(\beta=-.02, n s)$ than the total effect shown in Table $1(r=.19, p<.01)$. Thus, egoistic motivation and a lack of trust fully mediated the link between anxiety and controlling caregiving. ${ }^{4}$

Summary. Taken together, the results of Phase 1 provide clear evidence for attachment style differences in caregiving patterns. Secure attachment (low avoidance and low anxiety) was associated with more effective caregiving overall, and insecure attachment (high anxiety and/or high avoidance) was associated with various forms of ineffective care. The primary goal of Phase 1, however, was to identify the mechanisms that may mediate the link between attachment style and caregiving. Results reveal that a unique pattern of motives, skills, and resources can explain why people with different attachment styles care for their partner in particular ways. Specifically, avoidant individuals appear to be unresponsive and controlling caregivers at least partly because they do not possess adequate knowledge about how to support others, they are not prosocially oriented toward others, and they lack a sense of relationship interdependence and trust. Analyses also suggest that anxious individuals may be compulsive (overinvolved) and controlling caregivers at least partly because of their egoistic motivations for providing care, their lack of relationship trust, and their sense of relationship interdependence.

\section{Phase 2: Experimental Session}

Phase 2 of this investigation has three specific aims. First, because individuals might not be able to accurately report their own caregiving behavior, an important sequel to Phase 1 was to examine what people actually do when confronted with a situation in which a romantic partner is experiencing stress and is in need of support. Thus, we brought our couples back to the lab, where we created a stressful event for one member of the couple and then examined the caregivers' behavioral responsiveness to need through the use of written notes and observable "checking" be- havior. Our second goal was to examine the degree to which the mediators identified in Phase 1 were also important for explaining individual differences in caregiving behavior in a specific support episode. Our final goal was to provide a deeper understanding of what it means to be a good caregiver by examining responsiveness to need.

From an attachment theoretical perspective, good caregivers are those individuals who are able to effectively restore their partner's felt security when it is needed-by facilitating problem resolution and the alleviation of distress. In the infant attachment literature, maternal sensitivity has been shown to be a key feature of secure mother-infant dyads; sensitive mothers not only perceive their children's cues appropriately but also respond appropriately on the basis of the needs of their children (e.g., Ainsworth et al., 1978; George \& Solomon, 1999). Thus, responding to an attached partner's needs as they arise should be a key marker of effective caregiving in adult intimate relationships. Responding to need involves the provision of the amount and type of support that is required in a given situation-as dictated by the partner's needs (Cutrona \& Russell, 1990). Caregiving that is provided out of context (such as when a partner is not stressed and does not need it) is likely to go unrecognized or to be unwanted by the recipient and may be one reason why the support efforts of caregivers (although intended to be helpful) may sometimes have a negative impact on support recipients (e.g., Dakof \& Taylor, 1990).

We believe that responsiveness-caregiving that is contingent on the partner's need-should be a key element of effective caregiving in adult intimate relationships, in much the same way that it is in parent-child relationships (Clark, Fitness, \& Brissette, 2000; Clark et al., 1987; Kunce \& Shaver, 1994). Therefore, the purpose of the second phase of the study was to obtain behavioral evidence of caregivers' responsiveness to their partner's needs through the use of an experimental methodology. To examine responsiveness, we created high and low need for support conditions by leading one member of the couple to believe that his or her

\footnotetext{
${ }^{3}$ The betas shown in Figure 2 did not change in significance when this direct path (nor any direct path in subsequent model testing) was added to the model.

${ }^{4} \mathrm{We}$ conducted an additional series of analyses to examine the interaction of anxiety and avoidance in predicting each of the caregiving and mediating variables. Results revealed two significant Anxiety $\times$ Avoidance interactions predicting responsive caregiving, $\Delta R^{2}=.02$, $t(188)=1.96, p<.05$, and relationship interdependence, $\Delta R^{2}=.03$, $t(188)=2.66, p<.01$. To explore these interactions, we plotted the simple slope of anxiety (on each dependent variable) at high and low levels of avoidance (one standard deviation above and below the mean on avoidance). Results indicated that caregivers who were low in avoidance tended to engage in responsive caregiving behaviors regardless of their level of anxiety; however, those who were high in avoidance tended to become more responsive as their level of anxiety increased $(\beta=.22, p<.10)$. A similar pattern occurred for interdependence. Those who were low in avoidance reported high levels of interdependence regardless of their level of anxiety; however, those who were high in avoidance reported greater interdependence as their level of anxiety increased $(\beta=.40, p<.001)$. These results suggest that although avoidant individuals tended, in general, to be unresponsive caregivers and to report low levels of interdependence, dismissing avoidant caregivers (who are low in anxiety) were less responsive and reported lower levels of interdependence than did fearful avoidant caregivers (who are high in anxiety).
} 
partner was either extremely nervous about performing an upcoming task (high need condition) or not very nervous at all about the upcoming task (low need condition). By manipulating the support recipients' need for support, we created the necessary conditions for studying responsiveness.

This study involves a quasi-experimental design, with attachment style and manipulated need as the independent variables. The primary dependent variable was the degree to which caregivers provided support (as assessed in a spontaneous note written to the partner). Additional dependent measures assessed the degree to which caregivers monitored a romantic partner's need for support (by checking for messages from the partner) and the degree to which caregivers were self-focused when a romantic partner was experiencing a stressful situation.

\section{Hypotheses}

\section{The Effect of Need on Behavioral Measures of Caregiving}

Because the caregiving system should be activated in response to a partner's distress (Collins \& Feeney, 2000; Kunce \& Shaver, 1994), caregivers should provide more support when their partners express high levels of distress (when the attachment system has been activated with high intensity) and less support when their partners express low levels of distress. Thus, we hypothesized that caregivers would write more supportive notes, be less self-focused, and be more attentive to their partners in the high need condition than in the low need condition.

\section{Attachment Style Predicting Behavioral Measures of Caregiving}

We expected that the associations between attachment style and caregiving observed in Phase 1 with self-reported behaviors would be seen in Phase 2 with observable behaviors. However, we expected that the manipulation of the caregiver's knowledge of his or her partner's need for support would moderate the association between attachment style and caregiving.

Note support and attention to need. We expected that caregiver avoidance would be negatively associated with responsive caregiving (as assessed in the written notes and attention to need measure). However, we expected that this association would be stronger in the high need condition (when caregivers are led to believe that their partners are distressed) than in the low need condition. This hypothesis is consistent with theory and previous research (e.g., Simpson et al., 1992) suggesting that avoidant individuals are likely to dismiss or devalue expressions of distress as an emotion regulation strategy.

Because caregivers who are high in anxiety exhibit a mixed caregiving style, their caregiving behaviors in a specific support episode were more difficult to predict. First, because anxious individuals tend to be hypersensitive to social approval and worried about rejection and abandonment, they may view their partner's predicament as an opportunity to meet or express their own attachment needs (through their support behavior). This speculation is consistent with the results of Phase 1 , which indicated that anxious individuals are compulsive caregivers at least in part because of their selfish motivations. Therefore, there may be a positive association between caregiver anxiety and note support (and attentiveness) in both the high and low need conditions. A second possibility is that anxious caregivers will respond appropriately to their partner's needs; that is, caregiver anxiety may be positively associated with the provision of care in the high need condition but not in the low need condition. This hypothesis is supported by a recent study (Collins \& Feeney, 2000) that showed that anxious individuals do respond supportively to their partners when the partners make their needs clear and direct. Because partners' needs are clear in this study (as a result of the experimental manipulation), anxious individuals may have no difficulty recognizing them and responding appropriately.

State self-focus. Avoidant individuals tend to minimize the importance of attachment needs, feel uncomfortable with dependency, and dismiss expressions of distress. Therefore, we expected caregiver avoidance to be positively associated with self-focus, because avoidant individuals should be motivated to direct their attention away from their partner (who is undergoing a potentially distressing event). However, we expected this association to be strongest in the high need condition (when caregivers have clear knowledge that their partner is distressed) and weaker in the low need condition (when the partner is not thought to be distressed).

Again, the pattern for anxious individuals in a specific support situation was more difficult to predict. As shown in Phase 1, anxious attachment was associated with higher levels of chronic self-focus (see Table 1). Thus, we might expect that anxiety would be positively associated with self-focus in a specific behavioral interaction. However, because anxious individuals tend to be hypersensitive to their partner's approval (and, hence, their partner's moods) and overinvolved caregivers, we expected that this association would be weaker in the high need condition (when their partner is clearly distressed). In fact, in this particular setting, anxious individuals may focus on the partner's distress in an effort to meet other relationship goals (e.g., developing closeness and interdependence).

\section{Proposed Mediators of the Links Between Attachment Style and Caregiving Behaviors}

Although the primary goal of this phase was to examine the moderating effects of partner need on the associations between attachment style and caregiving, a secondary goal was to explore potential mediators of the links between attachment style and observed caregiving behaviors. We expected that the mediators that emerged as important in explaining the associations between attachment style and self-reported caregiving behaviors in Phase 1 would also explain the links between attachment style and observable caregiving behaviors in Phase 2.

\section{Method}

\section{Overview}

Each member of the couple was assigned to the role of either a caregiver or a support recipient. To create a stressful context within which to examine caregiving behavior, we asked the support recipient to prepare and give a videotaped speech. We manipulated the support recipient's need for support by giving the caregiver an opportunity to see a rating form, ostensibly filled out by the support recipient, indicating that the support recipient was either extremely nervous (high need condition) or not very nervous (low need condition) about having to give a speech. The caregiver 
was then given an opportunity to write a note to his or her partner (as a behavioral measure of support and caregiving), and the supportiveness of this note was rated by the support recipient and by three independent coders. During a 10 -min period while the caregiver was working on a cognitive activity (which included a measure of state self-focus) and while the support recipient was preparing for his or her speech, we assessed the caregiver's attentiveness to his or her partner's needs by counting the number of times the caregiver checked a computer monitor for messages (requesting help with the speech task) from his or her partner.

\section{Participants}

One hundred fifty-nine couples from Phase 1 participated in the experimental phase of the study, which took place approximately 1 week after the questionnaire session. ${ }^{5}$ Of these 159 couples, 90 men and 69 women were assigned to the caregiver role. Six couples were excluded from data analyses, either because of suspicion or because they did not notice the experimental manipulation. Three additional couples were excluded from the attention to need and self-focus analyses, either because their partners inadvertently entered the observation room or because the caregiver was attending to an infant while the measures were being taken.

\section{Procedure}

When couple members arrived at the laboratory, the experimenter explained that they would be helping us learn about how people think and feel when they are participating in various types of activities. The couple was told that each person had been randomly assigned to participate in one individual activity, after which they would participate in a few joint activities.

Presentation of stressor. The person who was assigned to the role of the support recipient was told that he or she had been randomly selected to participate in an individual activity that involved giving a speech (which would be videotaped and rated by peers). The instructions were intended to create a stressful situation for the support recipient so that we would have an appropriate context within which to examine caregiving behavior. The person assigned to the role of the caregiver was told that he or she had been randomly selected to participate in a cognitive task-an individual activity that involved the completion of some puzzles (e.g., word searches, mazes). The experimenter then escorted the support recipient to a "speech preparation" room and gave him or her some questionnaires to assess his or her thoughts and feelings about the upcoming speech task. The experimenter then returned to the caregiver to manipulate need for support.

Need manipulation. Each couple was randomly assigned to either a high need or a low need condition before arriving to the study. To manipulate need, we showed the caregiver a rating form that had ostensibly been completed by his or her partner (the speech giver). On the top portion of this form, the partner had been asked to answer the following questions on a scale ranging from 1 (not at all) to 7 (extremely): "How nervous are you about performing this public speaking activity?" and "How difficult do you think it is to perform this public speaking activity?" Before the couple arrived for the study, the top portion of this form had already been completed for the speech-giver. If the couple had been randomly assigned to the high need condition, then a " 6 " was circled for both the nervousness and difficulty ratings. Conversely, if the couple had been randomly assigned to the low need condition, then a " 2 " was circled for both questions.

To ensure that the caregiver saw his or her partner's ratings, the experimenter asked the caregiver to complete the bottom portion of the same form, in which the caregiver was asked to rate two comparable questions (e.g., "How nervous would you be if you were the person selected to perform the public speaking activity?"). The experimenter then left the room to give the caregiver some time to answer the questions and to review his or her partner's responses.

Note support measure. After several minutes, the experimenter informed the caregiver that he or she would begin the cognitive activity as soon as the support recipient was finished with his or her preactivity questionnaires. At this time, the experimenter explained that most people like to use the extra time to send a note to their partners before they begin preparing for the speech. The caregiver was shown a stack of note cards and writing materials and was told that he or she could write anything he or she wanted, then put the note card in an envelope and seal it so that it would be private. The experimenter then left the room for approximately 5 min. (Six caregivers chose not to write a note; 4 were assigned to the low need condition, and 2 to the high need condition.) During this time, the experimenter asked the support recipient to begin preparing for his or her speech.

Instructions for cognitive activity. Next, the experimenter returned to the caregiver to retrieve his or her note and provide instructions for the cognitive activity. The primary purpose of this cognitive task was to create a situation that was competing for the caregiver's attention. The caregiver was given a folder of puzzles and was informed that at the end of the study, the 2 people who solved the most puzzles would receive a $\$ 25$ prize.

State self-focus measure. The first "puzzle" that the caregiver completed was actually the Linguistics Implication Form, a 20-item measure of state self-focus developed by Wegner and Giuliano (1980). The caregiver was asked to complete sentences by choosing from one of three pronoun alternatives. For example, the caregiver read the sentence, "The sun went in just as ___ decided to lay outside," and then chose either $I$, she, or we to complete the sentence. Following Salovey (1992), we assigned a score of 2 to sentences completed with a first-person singular pronoun, a score of 0 to sentences completed with third-person pronouns, and an intermediate score of 1 to sentences completed with a first-person plural pronoun (e.g., we, us, or our). Thus, self-focus scores could range from 0 to 40 . In this sample, scores ranged from 8 to $40(M=24.35, S D=5.39)$.

Instructions for attention-to-need measure. To assess attention to need, we adapted a methodology developed by Clark and her colleagues (Clark et al., 1986). The experimenter explained to the caregiver that a computer had been set up in the rooms so that his or her partner could send messages while preparing for the speech. The experimenter explained that things were set up this way because some people like to ask their partners for help if they get stuck or start feeling bad while preparing for the speech. The experimenter explained that the caregiver can feel free to get up and reply if he or she receives a message and wishes to do so. The caregiver's desk was facing a wall, and the computer was strategically placed behind him or her, against the opposite wall. Thus, the caregiver had to physically turn around to check the computer for messages from his or her partner.

Attention-to-need measure. The experimenter left the room and videotaped the caregiver from the observation room for $10 \mathrm{~min}$. Two independent observers later watched each tape and counted the number of times the caregiver turned to check the computer monitor for messages. (No messages ever appeared.) Interrater agreement was $92 \%$; the few discrepancies among the observers' counts (12 cases) were resolved by a third rater. Scores on this measure ranged from 0 to 12 checks $(M=1.52$,

\footnotetext{
${ }^{5}$ Thirty-five of the original 194 couples did not participate in Phase 2. The majority of these couples did not return because of difficulties coordinating schedules with their partners. Eight of these couples did return for Phase 2 but terminated their participation on hearing the speech instructions. Exploratory analyses revealed no significant differences in dating length, attachment style, or age between couples who participated in Phase 2 and those who did not. However, the caregivers of couples who participated were more responsive $(M=0.05)$ than those who did not participate $(M=-0.24), t(192)=2.01, p<.05$. The caregivers who participated were also higher in interdependence $(M=0.03)$ than those who did not participate $(M=-0.16), t(192)=2.07, p<.05$. Finally, the support recipients of couples who participated reported being more satisfied with their relationship $(M=6.51)$ than did those who did not participate $(M=5.75), t(192)=3.25, p<.001$.
} 
$S D=2.16$ ). While the caregiver's attentiveness was being assessed, the experimenter delivered the caregiver's note to the support recipient.

Note evaluation form. At the end of the 10 -min period, the support recipient was given a note evaluation form to complete. On this form, the support recipient made three general ratings assessing emotional support ("Overall, how much emotional support did your partner provide in his/her note? By emotional support we mean affection, compassion, understanding, reassurance, compliments, etc."), instrumental support ("Overall, how much actual help or assistance with the speech task itself did your partner provide in his'her note?"), and negative support ("Overall, how negative, critical, or unsupportive was your partner's note?"). The support recipient also completed a 13-item measure of perceived support $(\alpha=.95)$, which assessed the supportive impact of the note as subjectively perceived (e.g., "My partner's note makes me feel better"). All ratings were made on 5 -point scales with appropriate anchors.

The caregiver was also given a questionnaire (including the manipulation check) to complete. Then the experimenter ended the study, fully debriefed the couple, and asked for permission to keep the caregiver's note so that it could be anonymously coded for content.

Coding notes. Each note was coded by three trained raters who were unaware of the study hypotheses, participants' attachment characteristics, and experimental condition. To assess interrater reliability, we computed intraclass correlations (ICCs; McGraw \& Wong, 1996) for all coded dimensions. The average of the three observers' ratings were used in data analysis. The trained raters made the same three general ratings made by the support recipients assessing emotional support (ICC $=.88$ ), instrumental support (ICC $=.89$ ), and negative support $(\mathrm{ICC}=.90)$. All ratings were made on the same 5 -point scales.

To obtain the most valid and concise measures of note support to be used in data analysis, we combined some of the support recipients' and observers' note ratings. First, recipient and observer ratings of emotional support and negative support were highly intercorrelated (average $r=.42$, all $p \mathrm{~s}<$ .001 ). Therefore, we summed these four ratings to create an overall index of emotional support (negative support was reverse coded). Second, we summed the recipient and observer ratings of instrumental support ( $r=$ $.23, p<.01$ ) to form an overall index of instrumental support. Finally, the support recipient's perceived support index (which measured the recipient's personal thoughts and feelings about his or her partner's note) was retained as a third and separate measure of note support.

\section{Results and Discussion}

\section{Manipulation Check}

We conducted $t$ tests to verify the effectiveness of the experimental manipulation. Results revealed that caregivers did, in fact, rate their partners as being more nervous about the speech task in the high need $(M=5.84)$ than in the low need condition $(M=3.36), t(151)=-12.57, p<.001$. They also rated the speech task as being more difficult for their partners in the high need $(M=4.46)$ than in the low need condition $(M=3.05), t(151)=$ $-5.61, p<.001$.

\section{Need Condition and Attachment Style Predicting Behavioral Measures of Caregiving}

Hypotheses regarding the effects of experimental need condition and attachment style on the behavioral measures of caregiving were tested using hierarchical regression analyses in which need condition, caregiver avoidance, and caregiver anxiety were entered on Step 1 and the Avoidance $\times$ Condition and Anxiety $\times$ Condition interactions were entered on Step 2. Results of these analyses are presented in Table 3. For descriptive purposes, the zero-
Table 3

Hierarchical Regression Analyses Predicting Observed Caregiving Behaviors

\begin{tabular}{|c|c|c|c|c|}
\hline $\begin{array}{l}\text { Caregiving behavior } \\
\text { and predictor }\end{array}$ & $b$ & $\beta$ & $\Delta R^{2}$ & $\begin{array}{c}\text { Total } \\
R^{2}\end{array}$ \\
\hline \multicolumn{5}{|l|}{ Emotional support } \\
\hline Step 1 & & & $.093 * *$ & $.093 * * *$ \\
\hline Need condition ${ }^{2}$ & $1.209^{* *}$ & $.229 * *$ & & \\
\hline Avoidance & $-0.103 \dagger$ & $-.138 \dagger$ & & \\
\hline Anxiety & $0.135 *$ & $.185^{*}$ & & \\
\hline Step 2 & & & .010 & $.103 * *$ \\
\hline Need condition & $1.270^{* *}$ & $.241 * *$ & & \\
\hline Avoidance & 0.101 & .136 & & \\
\hline Anxiety & 0.041 & .056 & & \\
\hline Need $\times$ Avoidance & -0.140 & -.129 & & \\
\hline \multirow{2}{*}{\multicolumn{5}{|c|}{ Instrumental support }} \\
\hline & & & & \\
\hline Step 1 & & & .009 & .009 \\
\hline Need condition & 0.230 & .078 & & \\
\hline Avoidance & 0.021 & .050 & & \\
\hline Anxiety & 0.006 & .014 & & \\
\hline Step 2 & & & $.080 * *$ & $.089 * *$ \\
\hline Need condition & 0.213 & .072 & & \\
\hline Avoidance & $0.294 * *$ & $.707 * *$ & & \\
\hline Anxiety & $-0.215^{*}$ & $-.528^{*}$ & & \\
\hline Need $\times$ Avoidance & $-0.189^{* *}$ & $-.311 * *$ & & \\
\hline Need $\times$ Anxiety & $0.162 *$ & $.246^{*}$ & & \\
\hline \multicolumn{5}{|l|}{ Perceived support } \\
\hline Step 1 & & & $.045 \dagger$ & $.045 \dagger$ \\
\hline Need condition & $0.380^{* *}$ & $.208 * *$ & & \\
\hline Avoidance & -0.005 & -.021 & & \\
\hline Anxiety & 0.015 & .060 & & \\
\hline Step 2 & & & $.032 \uparrow$ & $.077 *$ \\
\hline Need condition & $0.461 * *$ & $.252 * *$ & & \\
\hline Avoidance & $0.129 *$ & $.501 *$ & & \\
\hline Anxiety & -0.008 & -.032 & & \\
\hline Need $\times$ Avoidance & $-0.092 *$ & $-.244 *$ & & \\
\hline Need $\times$ Anxiety & 0.018 & .044 & & \\
\hline
\end{tabular}

a All need conditions were coded as $0=$ low need, $1=$ high need. $\dagger p<.10$ (marginally significant). ${ }^{*} p<.05 . \quad * * p<.01 . \quad{ }^{* * *} p<$ .001

order correlations between the caregiver's attachment dimensions and all dependent variables are shown (separately for the low and high need conditions) in Table 4.

Note support. As shown in Table 3, results revealed two significant main effects of need condition, predicting both emotional note support, $t(141)=2.85, p<.01$, and perceived note support, $t(141)=2.51, p<.01$. As predicted, caregivers' notes were rated as being more emotionally supportive as their partners' needs increased. In addition, support recipients perceived that their partners' notes were more supportive when the caregivers believed that their partners were more distressed (in the high need condition). Contrary to expectations, however, this hypothesis was not confirmed for instrumental support.

Results also revealed two main effects of attachment style predicting emotional note support (see Table 3). Anxious caregivers were rated as being more emotionally supportive in their notes, $t(141)=2.29, p<.05$, and avoidant caregivers were rated as being somewhat less emotionally supportive, $t(141)=-1.71, p<$ .10. There were no main effects of caregiver avoidance or caregiver anxiety in predicting instrumental support or perceived note support. 
Table 4

Correlations Between Caregiver's Attachment Style and Caregiving Behaviors in Low and High Need Conditions

\begin{tabular}{lcc}
\hline $\begin{array}{c}\text { Caregiving behavior } \\
\text { and condition }\end{array}$ & Avoidance & Anxiety \\
\hline Low need condition & & \\
Emotional support & -.04 & .15 \\
Instrumental support & $.25^{*}$ & -.13 \\
Perceived support & .14 & .05 \\
State self-focus & -.11 & .16 \\
Attention to need & -.05 & -.11 \\
High need condition & $-.26^{*}$ & $.24^{*}$ \\
Emotional support & -.17 & $.21 \dagger$ \\
Instrumental support & $-.22 \dagger$ & .08 \\
Perceived support & -.02 & -.01 \\
State self-focus & .14 & .03 \\
Attention to need & & \\
\hline
\end{tabular}

Note. $n=73$ in low need condition and $n=74$ in high need condition for note ratings and self-focus measure; $n=74$ in low need condition and $n=76$ in high need condition for attention-to-need measure.

$\dagger p<.10$ (marginally significant). $* p<.05$.

Consistent with predictions, results revealed two significant Caregiver Avoidance $\times$ Condition interactions predicting instrumental support, $t(139)=-2.78, p<.01$, and perceived note support, $t(139)=-2.17, p<.05$. As shown in Figure 3, caregiver avoidance was positively associated with the provision of instrumental support in the low need condition $(b=0.105, \beta=.260$, $p<.05$ ); however, there was a marginally significant tendency for caregiver avoidance to be negatively associated with instrumental support in the high need condition $(b=-0.084, \beta=-.197, p<$ .10). Likewise, as shown in Figure 4 , the notes written by caregivers in the high need condition were perceived by their partners as being less supportive as the caregivers' level of avoidance increased $(b=-0.055, \beta=-.239, p<.05)$; however, avoidance was not significantly related to perceived support in the low need condition $(b=0.037, \beta=.137, n s)$. In sum, caregiver avoidance was associated with relatively poor caregiving behaviors in the high need condition but not the low need condition. That is, avoidant caregivers did not increase their provision of support in response to their partner's increased distress. Although the pattern of associations between caregiver avoidance and emotional support was in the expected direction in both need conditions (see Table 4), the Avoidance $\times$ Condition interaction did not reach statistical significance.

As indicated in Table 3, results also revealed one significant Caregiver Anxiety $\times$ Condition interaction predicting instrumental support, $t(141)=2.36, p<.05$. As shown in Figure 5, caregiver anxiety was positively associated with the provision of instrumental support in the high need condition $(b=0.109, \beta=.235, p<$ $.05)$; however, caregiver anxiety was not significantly related to instrumental support in the low need condition $(b=-0.053, \beta=$ $-.144, n s)$. There were no significant Anxiety $\times$ Condition interactions predicting emotional support or perceived support. However, as shown in the second column of Table 4, caregiver anxiety was positively associated with the provision of emotional support in the high need condition. ${ }^{6}$

State self-focus. Contrary to expectations, there were no main effects of need condition, caregiver avoidance, or caregiver anxi- ety in predicting state self-focus. Moreover, there were no Caregiver Avoidance $\times$ Condition or Anxiety $\times$ Condition interactions predicting state self-focus. Descriptive correlations for these analyses are presented in Table $4 .^{7}$

Attention to need. Contrary to expectations, results revealed no main effects of need condition, caregiver avoidance, or caregiver anxiety in predicting attention to need. In addition, there were no Caregiver Avoidance $\times$ Condition or Anxiety $\times$ Condition interactions predicting attention to need. ${ }^{8}$ Descriptive correlations for these analyses are presented in Table $4 .^{9}$

\section{Mediational Analyses}

The hypotheses regarding the mediators of the links between attachment style and the behavioral measures of caregiving (described above) were tested with SEM using procedures similar to those used in Phase 1. Separate mediational models were tested for each of the significant (or marginally significant) attachment effects obtained.

The first model explored the mediators of the two main effects of attachment style predicting emotional note support (the link between anxiety and increased provision of emotional support in the notes and between avoidance and decreased emotional support). To identify variables that met Baron and Kenny's (1986) criteria for being viable mediators, we began by examining the associations (in the overall sample) between emotional note support (our dependent variable in this model) and the seven mediat-

${ }^{6}$ Exploratory analyses examining the effects of attachment style and need condition predicting support recipients' and observers' ratings of emotional support separately revealed patterns of results that were consistent with the pattern reported above for the emotional support composite. The only noteworthy difference was a nonsignificant (instead of a marginal) main effect of caregiver avoidance predicting the observers' ratings of emotional note support. Additional exploratory analyses examining the effects of attachment style and need condition predicting support recipients' and observers' ratings of instrumental support separately also revealed patterns of results that were similar to those presented above for the composite instrumental support variable. The only difference in the overall pattern was a nonsignificant Anxiety $\times$ Condition interaction predicting the observers' ratings of instrumental note support. Exploratory analyses also revealed that there were no significant Anxiety $\times$ Avoidance interactions predicting note support, nor were there any significant Anxiety $\times$ Avoidance $\times$ Condition interactions. Finally, to increase our confidence that the significant patterns involving attachment style did not simply reflect the caregiver's satisfaction with his or her relationship, we reran all analyses controlling for relationship satisfaction. This did not change the significance or the nature of the interactions.

${ }^{7}$ Exploratory analyses revealed that there were no significant Anxiety $\times$ Avoidance or Anxiety $\times$ Avoidance $\times$ Condition interactions predicting state self-focus.

${ }^{8}$ Because the distribution of scores on the attention-to-need measure was skewed (skewness $=2.28$ ), we submitted the scores to a logarithmic transformation (attention $=\log _{10}$ [attention +1$]$ ). All analyses involving the attention-to-need measure were run twice, once using the original variable and another time using the transformed variable. Because the results remained the same for both variables, these and all subsequent analyses are presented using the original attention variable.

${ }^{9}$ Exploratory analyses revealed that there were no significant Anxiety $\times$ Avoidance or Anxiety $\times$ Avoidance $\times$ Condition interactions predicting attention to need. 


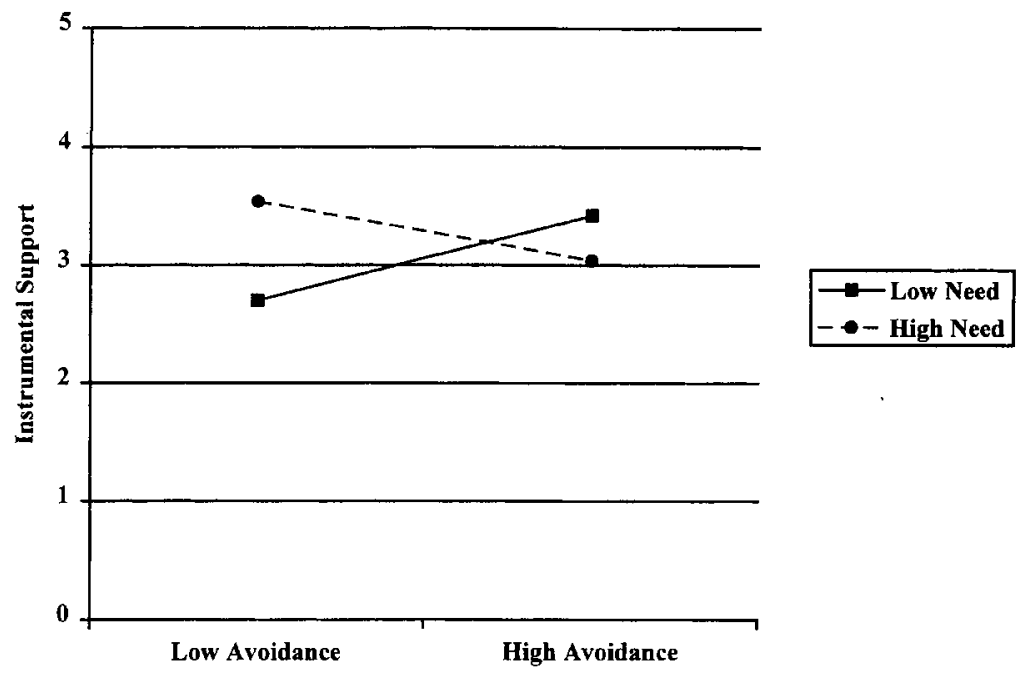

Figure 3. Relationship between caregiver avoidance and instrumental note support for caregivers in the high and low need conditions.

ing variables identified in Phase 1. These analyses revealed significant associations between emotional note support and only three of the seven proposed mediators $(r=.34, p<.001$, for prosocial orientation; $r=.30, p<.001$, for interdependence; $r=$ $-.17, p<.05$, for egoistic motives). Hence, the mediational model was specified as follows: The two attachment dimensions (avoidance and anxiety) were exogenous variables; prosocial orientation, interdependence, and egoistic motivation were the mediating variables; and emotional note support was the dependent variable. Guided by hypotheses and associations observed in Phase 1, we estimated paths from (a) avoidance to prosocial orientation and interdependence, (b) anxiety to interdependence and egoistic mo- tivation, and (c) all three mediating variables to emotional note support. Covariances were also drawn among the residuals of the mediating variables.

The goodness of fit statistics indicate that our model provided a good fit to the data, CFI $=.97, \mathrm{NNFI}=.90, \mathrm{SRMR}=.08, \chi^{2}(4$, $N=145)=7.28, n s$. This model appears in the top panel of Figure 6 (Model A). Consistent with hypotheses, the model indicates that (a) a lack of prosocial orientation and relationship interdependence mediated the link between avoidance and low levels of emotional note support and (b) higher levels of relationship interdependence mediated the link between anxiety and the provision of emotional note support. Although the fully mediated model provided a good

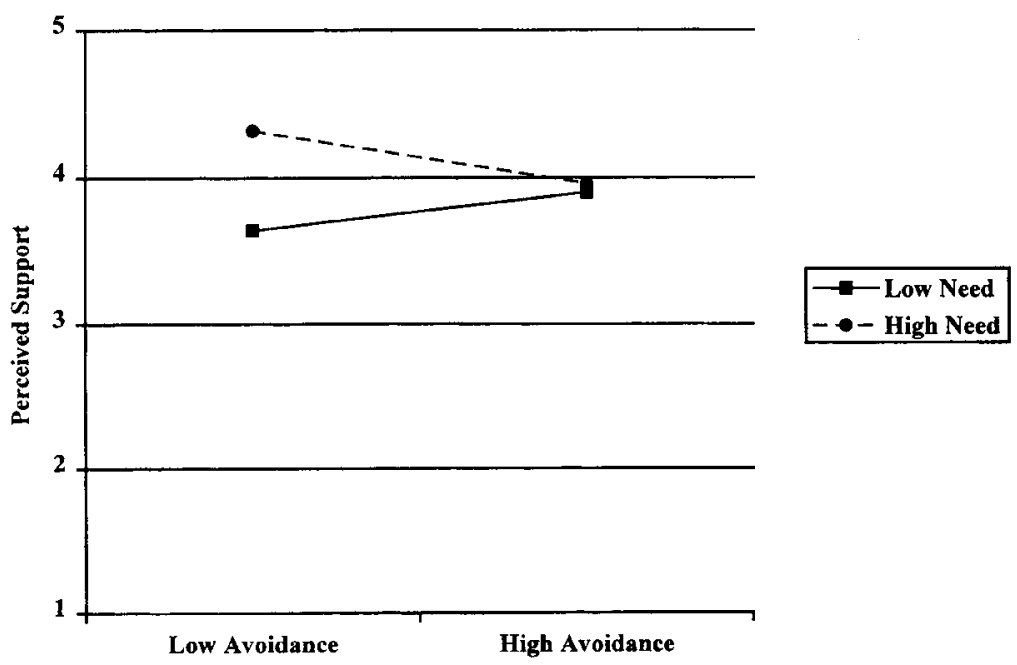

Figure 4. Relationship between caregiver avoidance and perceived note support for caregivers in the high and low need conditions. 


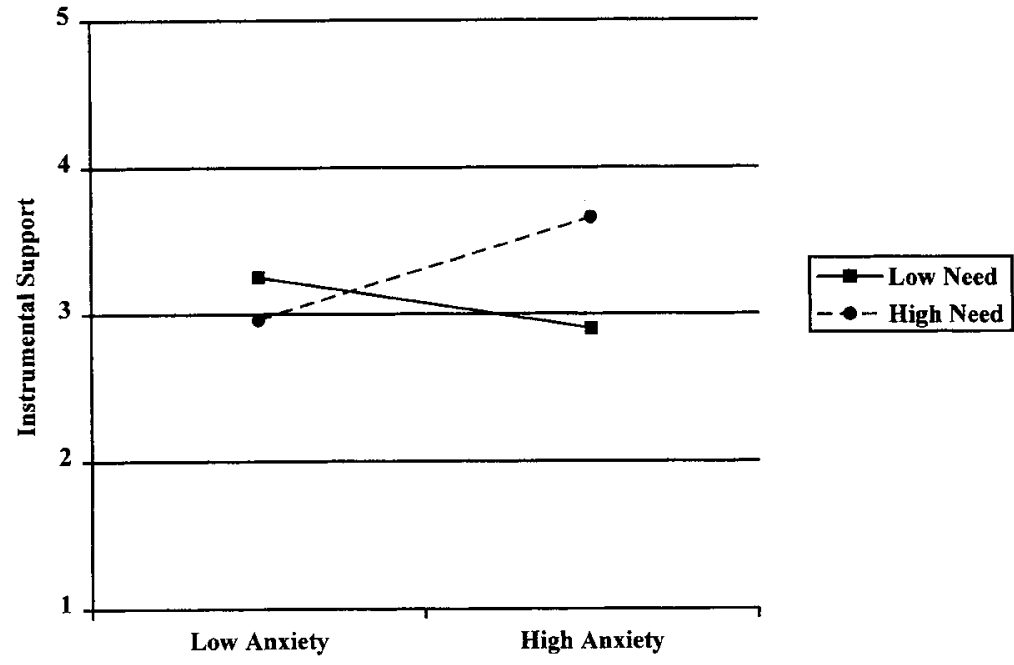

Figure 5. Relationship between caregiver anxiety and instrumental note support for caregivers in the high and low need conditions.

fit to the data, direct paths were added (one at a time) to determine whether model fit would be significantly improved. First, we added a direct path from avoidance to emotional note support.
Model fit was not significantly improved, $\Delta \chi^{2}(1, N=$ $145)=2.52, n s$, and the direct path was not significant $(\beta=.15$, $n s)$. Therefore, a lack of prosocial orientation and interdependence

A.

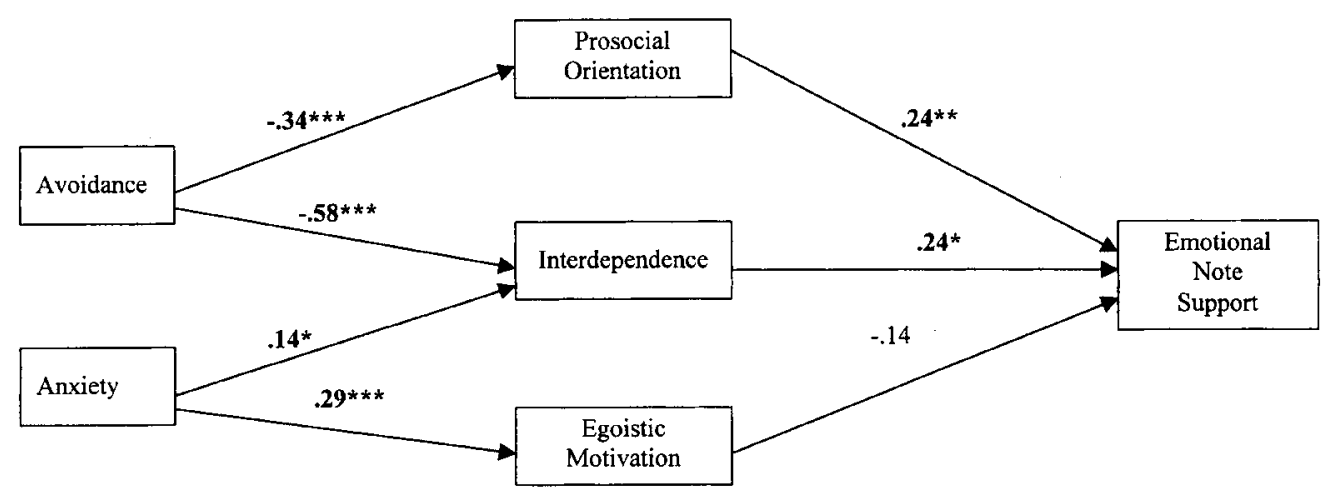

B.

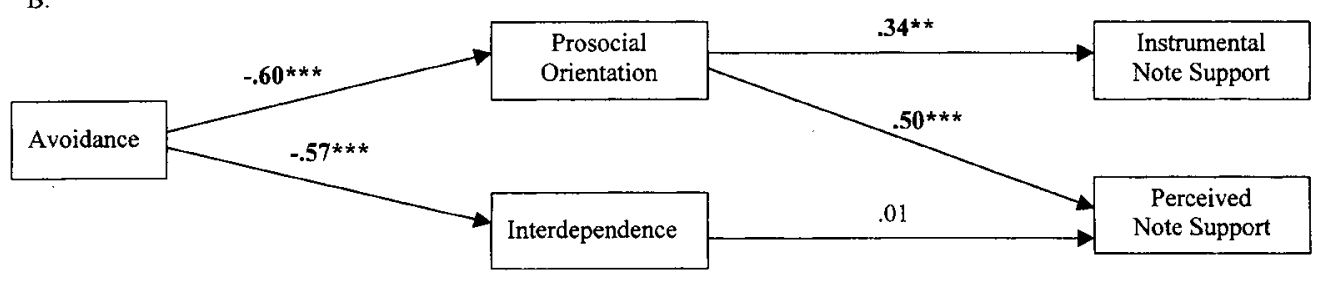

Figure 6. Mediational models. Model $\mathrm{A}(N=145)$ represents the mediational model for the full sample. Model B $(N=72)$ represents the mediational model for the high need condition only. Path values represent standardized regression coefficients. ${ }^{*} p<.05 .{ }^{* *} p<.01 .{ }^{* * *} p<.001$. 
fully explained the link between avoidance and low emotional support. Next, we added a direct path from anxiety to emotional note support. Model fit was significantly improved, $\Delta \chi^{2}(1, N=$ $145)=4.65, p<.05$, and the direct path was significant $(\beta=.17$, $p<.05$ ). Thus, relationship interdependence only partially mediated the link between anxiety and increased emotional note support.

The next model examined the mediators of the link between caregiver avoidance and lower levels of instrumental support and perceived note support in the high need condition. Again, to identify viable mediators, we began by examining the correlations among the seven potential mediating variables and the note support variables in the high need condition (see lower panel of Table 5). These analyses reveal that (a) both prosocial orientation and interdependence were significantly associated with perceived note support and (b) both prosocial orientation and chronic self-focus were significantly associated with instrumental note support. However, because chronic self-focus was not associated with avoidance in Phase 1, this variable was not a viable mediator and was thus excluded. Therefore, guided by hypotheses and associations observed in Phase 1, the mediational model was specified as follows: Paths were specified from (a) avoidance to prosocial orientation and interdependence, (b) prosocial orientation to both instrumental and perceived note support, and (c) interdependence to perceived note support. A covariance was also added between the residuals of the two mediating variables.

The goodness of fit statistics indicate that our model provided a good fit to the data, CFI $=1.00, \mathrm{NNFI}=1.07, \mathrm{SRMR}=.00, \chi^{2}(3$, $N=72)=1.15, n s$. This model, which appears in the bottom panel of Figure 6 (Model B), indicates that a lack of prosocial orientation mediated the link between caregiver avoidance and low levels of both instrumental and perceived support in the high need condition. Relationship interdependence did not emerge as a mediator. Next, direct paths were added to the model. First, a direct path was added from avoidance to instrumental note support. Model fit was not significantly improved, $\Delta \chi^{2}(1, N=72)=.04$, $n s$, and the direct path from avoidance to instrumental note support was not significant $(\beta=.03, n s)$. Next, a direct path was added from avoidance to perceived note support. Again, model fit was not significantly improved, $\Delta \chi^{2}(1, N=72)=.96, n s$, and the direct path was not statistically significant $(\beta=.13, n s)$. Taken together, these analyses indicate that a lack of prosocial orientation fully explained the links between avoidance and lower levels of instrumental and perceived note support in the high need condition.

Our next analysis sought to identify the mediators of the link between caregiver avoidance and increased provision of instrumental note support in the low need condition. However, because none of the proposed mediating variables was significantly associated with the provision of instrumental note support in the low need condition (see upper panel of Table 5), there existed no viable mediators, and further analyses were not conducted for this effect.

Our final model examined the mediators of the link between caregiver anxiety and increased provision of instrumental support in the high need condition. Correlational analyses reveal that both chronic self-focus and prosocial orientation were associated with the provision of instrumental support in the high need condition (see Table 5). However, because anxiety was not associated with prosocial orientation in Phase 1, only chronic self-focus was a viable mediator. Hence, a mediational model was specified in which paths were estimated from anxiety to chronic self-focus and from chronic self-focus to instrumental note support. The goodness of fit statistics indicated that this model provided a poor fit to the data, $\mathrm{CFI}=.87, \mathrm{NNFI}=.61, \mathrm{SRMR}=.11, \chi^{2}(1, N=72)=1.92$, $n s$. Although caregiver anxiety was a significant predictor of chronic self-focus $(\beta=.26, p<.05$ ), the path from chronic self-focus to instrumental note support was nonsignificant $(\boldsymbol{\beta}=$ $.21, n s)$. When the direct path from anxiety to instrumental support was added, it was also nonsignificant $(\beta=.17, n s)$. Thus, the tendency for anxious individuals to provide high levels of emotional support in the high need condition was not explained by any of the mediators measured at Phase 1.

\section{Summary}

Taken together, the results of Phase 2 provide encouraging support for a number of our hypotheses. First, these data provide evidence for a normative increase in caregiving behavior in response to need. Specifically, caregivers were more emotionally supportive and were perceived by their partners (who knew nothing about the need manipulation) as being more supportive when they believed that their partners were more distressed about the speech task. This pattern is consistent with attachment theory's postulate that caregivers act with more urgency and provide a greater degree of support when the attachment system is activated with higher intensity. At the same time, however, results reveal

Table 5

Correlations Between Mediating Variables and Caregiving Behaviors in High and Low Need Conditions

\begin{tabular}{|c|c|c|c|c|c|c|c|}
\hline $\begin{array}{l}\text { Caregiving behavior } \\
\text { and condition }\end{array}$ & $\begin{array}{l}\text { Chronic } \\
\text { self-focus }\end{array}$ & $\begin{array}{c}\text { Support } \\
\text { knowledge }\end{array}$ & $\begin{array}{c}\text { Prosocial } \\
\text { orientation }\end{array}$ & $\begin{array}{l}\text { Exchange } \\
\text { orientation }\end{array}$ & Interdependence & Trust & $\begin{array}{c}\text { Egoistic } \\
\text { motivation }\end{array}$ \\
\hline \multicolumn{8}{|l|}{ Low need } \\
\hline Emotional & .03 & -.02 & $.30 * *$ & .15 & $.26^{*}$ & .08 & -.18 \\
\hline Instrumental & .07 & .15 & .04 & .13 & -.09 & -.01 & -.01 \\
\hline Perceived support & -.05 & .07 & $.23 *$ & .08 & .07 & .02 & -.18 \\
\hline \multicolumn{8}{|l|}{ High need } \\
\hline Emotional & .15 & .13 & $.51^{* * *}$ & $-.20 \dagger$ & $.38 * * *$ & .13 & -.13 \\
\hline Instrumental & $.23^{*}$ & .18 & $.34^{* *}$ & .04 & .16 & .05 & .16 \\
\hline Perceived support & .05 & -.01 & $.50^{* * *}$ & -.18 & $.25 *$ & .11 & -.15 \\
\hline
\end{tabular}

Note. $n=73$ in low need condition, and $n=74$ in high need condition.

$+p<.10$ (marginally significant). $* p<.05 . * * p<.01 . * * * p<.001$. 
that not all caregivers were equally responsive to their partner's distress.

Avoidant caregivers were instrumentally supportive in the low need condition but not in the high need condition, and their notes were perceived as being relatively unsupportive by their partners in the high need condition but not in the low need condition. In addition, avoidant caregivers were less likely to provide emotional support to their partners in the high need condition. Overall, avoidant individuals appeared to be the least supportive precisely when their partners needed support the most.

The opposite pattern was observed for caregiver anxiety. Anxious caregivers were instrumentally supportive in the high need condition, but anxiety was unrelated to instrumental support in the low need condition. These results support the hypothesis that anxious caregivers are supportive when they are led to believe that their partner has a clear need for support (see Figure 5). However, caregiver anxiety was also associated with the provision of emotional support in both need conditions. Thus, anxious caregivers did, in fact, support their partners during this specific behavioral episode. The complex pattern of findings is not surprising, given the mixed caregiving style associated with caregiver anxiety in the self-report literature and in Phase 1 of this investigation.

Finally, the mediators identified as important in Phase 1 also helped explain observable caregiving behavior in Phase 2 . Specifically, the relatively unresponsive caregiving behavior displayed by high avoidant individuals was mediated by their lack of relationship interdependence and prosocial orientation, and the relatively responsive caregiving behavior displayed by high anxious individuals was meditated, in part, by their higher levels of relationship interdependence. However, our Phase 1 mediators did not fully explain the pattern for anxious caregivers.

\section{General Discussion}

Although social support is a dyadic process that involves the interplay of both the attachment (support seeking) and caregiving systems, the purpose of this investigation was to focus the spotlight on the caregiver. In doing so, we sought to identify individual differences in caregiving patterns and to explore the personal and relationship factors that may explain these differences. In Phase 1, we used a questionnaire methodology to distinguish the caregiving patterns of individuals with different attachment styles and to shed light on the factors that may enhance or impede the provision of effective support and care. In Phase 2, we used a laboratory paradigm in which we experimentally manipulated the need for support and then observed caregivers' sensitivity and responsiveness to their partner's needs.

\section{Attachment Style Differences in Caregiving Patterns}

The results of this study support and extend the findings of previous studies indicating that attachment style is a significant and important predictor of social support and caregiving behavior in adult intimate relationships. Overall, attachment security (indicated by low levels of anxiety and avoidance) was associated with more effective, responsive forms of caregiving. Insecure attachment, on the other hand, was associated with ineffective caregiving patterns; however, the particular type of ineffective care depended on the particular type of insecurity.
Phase 1 revealed that attachment-related avoidance was associated with unresponsive and controlling forms of caregiving. Avoidant individuals reported that they lacked both sensitivity to their partner's signals and a willingness to provide physical comfort and nurturance in response to their partner's expressions of distress. When avoidant individuals do engage in caregiving activity, they tend to be somewhat controlling. Phase 2 corroborated these findings by revealing a general tendency for avoidance to be associated with low levels of emotional support in both the high and low need conditions. In addition, when avoidant individuals were clearly aware that their partners were distressed (in the high need condition), higher levels of caregiver avoidance were associated with less perceived support and instrumental support (although the association with instrumental support was a marginal trend). However, it is interesting to note that avoidant individuals were not uniformly neglecting. In the low need condition (when they were led to believe that their partner was not distressed), higher levels of caregiver avoidance were associated with increased instrumental support. Taken together, these findings reveal a striking pattern: Avoidant individuals provided the least support when their partner needed their support the most.

The pattern of results for avoidant caregivers is compatible with Simpson et al.'s (1992) study indicating that avoidant male caregivers provided less support to their partners as their partners' level of anxiety increased (see also Fraley \& Shaver, 1998). Our findings are also consistent with the infant literature, which suggests that mothers selectively attend to infant signals in ways that are compatible with the mother's own attachment organization (Cassidy, 2000; Main, Kaplan, \& Cassidy, 1985). For example, Escher-Graub and Grossman (1983, as cited in Cassidy, 2000) found that mothers of avoidant infants, who tend to be avoidant themselves (e.g., Ainsworth \& Eichberg, 1991; Benoit \& Parker, 1994; van IJzendoorn, 1995), withdraw from interaction when their infant is distressed but engage in interaction when their infant is content. In addition, George and Solomon $(1996,1999)$ found that mothers of avoidant children prefer to care for their children from a distance and tend to cognitively deactivate their caregiving system by dismissing or devaluing their children's attachment needs. In the current investigation, because we experimentally manipulated the degree to which adult support recipients were distressed and needed support, our results help to solidify the theory and data suggesting that avoidant individuals actively dismiss or devalue attachment needs and expressions of distress (Cassidy, 1994; Fraley, Davis, \& Shaver, 1998; Fraley, Garner, \& Shaver, 2000; George \& Solomon, 1999; Simpson et al., 1992). This emotion regulation strategy may function to deactivate the caregiver's own attachment/caregiving system and may also serve to deactivate the attachment system of the partner by requiring him or her to find alternative methods of dealing with distress.

Anxious individuals, on the other hand, appear to be telling a more complicated story. Phase 1 revealed that attachment-related anxiety was associated with overinvolved, intrusive, and controlling forms of caregiving. However, neither phase of our study suggests that anxious individuals are uniformly poor caregivers. In Phase 1, caregiver anxiety was unrelated to our composite measure of responsive caregiving, and in Phase 2, caregiver anxiety was associated with higher levels of emotional support in both the high and low need conditions and with higher levels of instrumental 
support in the high need condition (when the partner presumably needed support).

The finding that anxious caregivers provided emotional support regardless of their partner's level of distress may reflect their tendency to be overinvolved caregivers (as revealed in Phase 1). However, the fact that caregiver anxiety was associated with more instrumental support in the high need condition and less in the low need condition suggests that at least some aspects of their support behavior were appropriately contingent on their partner's needs. It is interesting to note, however, that their partners (the support recipients) did not subjectively experience these notes as more supportive (as indicated by the lack of association between caregiver anxiety and perceived note support; see Table 4). Given the compulsive and controlling caregiving pattern of anxious individuals revealed in Phase 1, it is possible that support recipients may have perceived these notes as excessive or perhaps out of sync with their needs. Unfortunately, we were unable to code for compulsive or controlling caregiving in the brief notes that we gathered. In fact, because we coded the notes in terms of their amount of emotional and instrumental content, excessive caregiving would have been rated as highly supportive. These results point to the need for new methodologies that are capable of capturing compulsive and controlling caregiving in the laboratory and for a more in-depth examination of the observed caregiving behavior of anxious individuals (perhaps over longer periods of time and in a variety of situations).

In sum, anxious individuals appear to be ineffective caregivers in that they tend to be intrusive and overinvolved, but they do not appear to be rejecting or broadly unresponsive to their partner's needs. This complex pattern of findings is compatible with recent work in the infant attachment literature. For example, mothers of anxious-ambivalent children (who are often classified as preoccupied with attachment) tend to interfere with infant exploration in an effort to keep their infants close to them (see Cassidy \& Berlin, 1994, for a review). Moreover, George and Solomon $(1996,1999)$ have shown that mothers of ambivalent children overemphasize and overinterpret their children's attachment cues, and they engage in caregiving strategies (characterized by confusion and uncertainty) that promote dependency.

\section{Mechanisms That Explain Attachment Style Differences in Caregiving}

The principle objective of our investigation was to go beyond the mere documentation of caregiving patterns and to identify the mechanisms that may help explain these patterns. We have suggested that the essence of effective caregiving-sensitively responding to needs as they arise-requires a constellation of skills, resources, and motivations that individuals may possess to varying degrees. In this study, we focused on relatively chronic personal characteristics of the caregiver and on relatively chronic characteristics of the caregiver's relationship with his or her romantic partner. We categorized these factors into particular types of skills (e.g., knowledge about how to support others), resources (e.g., cognitive resource resulting from a lack of self-focus), and motivations (e.g., relationship-specific egoistic motivations for helping one's partner) that may predict caregiving quality. Our results reveal that unique patterns of motives, skills, and resources can help us understand why people with different attachment styles care for their partners in the particular ways that they do.

First, which factors explained the tendency for avoidant adults to be unresponsive and controlling? Mediational analyses in Phase 1 suggest that avoidant adults may be unresponsive and controlling caregivers at least partly because they lack knowledge about how to support others, they lack prosocial orientation (empathy and communal orientation), and they fail to develop the deep sense of relationship closeness, commitment, and trust that appear to be critical for the motivation of caregiving behavior (Rusbult \& Buunk, 1993). Phase 2 corroborated these findings by revealing that a lack of prosocial orientation and interdependence mediated the link between avoidant attachment and low levels of emotional and instrumental support in a specific behavioral episode.

Taken together, these findings suggest that avoidant individuals have deficits in caregiving because they lack both the skills and the motivation necessary to be good caregivers. It is likely that having the opportunity to observe positive role models in one's own attachment history is one important way that individuals develop the requisite skills for caregiving. Because avoidant adults report a history of negative attachment experiences with rejecting caregivers and role models (Collins \& Read, 1990; Hazan \& Shaver, 1987), it makes sense that they have a more limited repertoire of caregiving strategies at their disposal. In addition, there is now mounting evidence that avoidant individuals are motivated to suppress activation of the attachment system (Fraley et al., 1998; Fraley \& Shaver, 1997). Although we do not yet know about the motivated organization of the caregiving system, we might speculate that any factors that increase the motivation to provide care to one's partner (e.g., a prosocial orientation toward others, relationship interdependence) conflict with avoidant adults' broader goal of keeping the attachment and caregiving systems in a deactivated state. Consistent with this idea, George and Solomon (1999) have found that rejecting mothers of avoidant infants are capable of cognitively deactivating their caregiving system.

Next, which mechanisms explained the tendency for anxious adults to be compulsive and controlling caregivers? Phase 1 analyses suggest that anxious adults may be compulsive and controlling caregivers at least partly because they possess a sense of relationship interdependence (they feel close and committed to their partners), but they simultaneously distrust their partners and are selfishly motivated in their caregiving attempts. Indeed, it is possible that the absence of a direct link between anxiety and responsive caregiving in Phase 1 is due to these individuals' conflicting tendencies to be both responsive and unresponsive, perhaps depending on the particular mediating force (selfish motives or feelings of concern for their partner's well-being) that takes precedence in a given situation. Phase 2 revealed that relationship interdependence partially mediated the link between anxious attachment and high levels of emotional support in a specific behavioral episode. These results suggest that anxious adults do possess some of the requisite skills and altruistic motives for being effective caregivers but that other conflicting, perhaps more selfish, motives may cause them to care for their partners in a compulsive, controlling, and inconsistent manner. For example, anxious individuals may lavish their partners with (even sometimes unwanted) care and support in an effort to ensure that their partners remain close and committed to the relationship. 
It is important to note that not all of the mediating variables that emerged in Phase 1 when we were predicting general caregiving patterns remained important in Phase 2 when we were predicting behavior in a specific laboratory situation. In retrospect, it makes good sense that general caregiver characteristics (assessed in Phase 1) do a better job of predicting general caregiving patterns than of predicting specific caregiving behavior. First, in the Phase 2 laboratory setting, there are a variety of situation-specific factors that may have contributed to the caregiver's behavior but were not measured in this study (e.g., the caregiver's mood, perceptions of the partner's ability to cope with the speech task, situation-specific motives such as feelings of obligation). Second, not all mediators can be expected to be salient and to drive behavior in every given support situation. For example, there may be situations in which avoidant individuals' lack of relationship interdependence drives their behavior and other contexts in which their lack of relationship trust most strongly predicts caregiving behavior. Thus, additional objectives for future research are to identify the contexts in which various mechanisms are likely to be more or less salient and to examine a variety of situation-specific mediational processes.

It is also important to note that even in Phase 1, the explanatory mechanisms did not fully mediate the link between caregiver anxiety and compulsive caregiving or the link between caregiver avoidance and unresponsive caregiving. Thus, there are likely to be other mediators that we failed to measure in this investigation. One mechanism that may underlie the caregiving pattern of anxious individuals may involve feelings of conditional acceptance (see Baldwin \& Sinclair, 1996). Specifically, anxious individuals may believe that their partner's love and acceptance of them is conditional on their provision of care. Another interesting mechanism involves inaccurate social construal processes on the part of the caregiver. For example, caregivers may use themselves as a standard when making social judgements about their partners (Dunning \& Hayes, 1996) and may mistakenly believe that their partner thinks and feels the way they do. As a result of this false consensus bias (Mullen et al., 1985), caregivers may impose their own coping style on their partners in stressful situations. For instance, avoidant individuals, who generally cope with stress by restricting acknowledgment of distress and by not seeking support from others (e.g., Ognibene \& Collins, 1998), may be neglecting caregivers because they inaccurately believe that their partner has a similar coping preference.

Although our goal was to identify the mechanisms that explain attachment style differences in caregiving, it is important to keep in mind that the associations among the mediating variables and caregiving outcomes are meaningful in their own right (irrespective of their links with attachment style) because they inform us about various factors that are associated with being an effective or ineffective caregiver in intimate relationships-a topic that has been largely neglected in the social support and close relationships literatures. Although we must withhold judgement about the relative importance of various skills, resources, and motivations in predicting caregiving outcomes until more studies examining the these mechanisms have been conducted, it is particularly noteworthy that prosocial orientation emerged as a strong predictor of caregiving in both phases of our investigation. Recall that our prosocial orientation composite assessed the degree to which the caregiver is willing to respond to other people's needs and desires (a communal orientation toward others; Clark et al., 1987) as well as the degree to which the caregiver is able to empathize with and take the perspective of other people. Although these factors have been shown to increase helping toward strangers (e.g., Batson et al., 1983, 1991; Clark et al., 1986, 1987), this study is among the first to show that empathy and communal orientation are also important predictors of social support and helping processes within intimate relationships. It is also interesting to note that another important predictor of caregiving (especially in Phase 1) was relationship interdependence, which was a measure of the caregiver's sense of closeness and commitment to his or her partner. The predictive ability of this variable in our study is consistent with previous research indicating that relationship commitment and closeness are important for motivating pro-relationship behaviors such as accommodation and a willingness to sacrifice (e.g., Aron et al., 1992; Rusbult \& Buunk, 1993). Our data suggest that social support and caregiving may be another special class of prorelationship behavior in which interdependent and committed relationship partners engage.

\section{Conclusions, Limitations, and Caveats}

Taken together, the results of this investigation provide strong evidence of attachment style differences in caregiving behavior in intimate relationships, and our confidence in these findings is bolstered by the multiple methodologies used in this study. These data also offer insight into the underlying factors that are responsible for these different caregiving patterns. Nevertheless, some limitations and caveats should be noted.

First, the relative lack of effects for the state self-focus and attention-to-need variables in Phase 2 were particularly surprising. The most likely explanation centers around the study design itself. Specifically, the attention-to-need and state self-focus measures were obtained after the caregivers had written their partner a note, and this design feature may have had a variety of unintended effects. For example, after writing their note, caregivers may have felt comfortable turning their attention to the puzzles (rather than to their partner) because they had already provided support to their partner in the note. Another possibility is that caregivers may have been checking the monitor not only out of a concern for responding to their partners' need but also because they expected a response to the note they had just written. And, finally, because the attention to need and self-focus measures were assessed later in the study period, they may have been less influenced by the need manipulation.

Second, because our a priori mediational models were modified on the basis of preliminary analyses of the associations among the study variables, these models are to some extent exploratory and must be replicated in future studies. It is also important to keep in mind that, with the exception of our manipulation of need in Phase 2, these data are correlational and cannot be used to draw unqualified causal inferences. The results of the mediational analyses are consistent with the underlying theoretical model suggesting that attachment style contributes to the development of certain chronic characteristics that, in turn, affect one's caregiving behavior toward one's partner. Nevertheless, we cannot rule out the possibility that some important variables were left unmeasured or that some other ordering of the variables is the "true" cause-effect sequence. Indeed, the true causal model is likely to include bidirectional effects and feedback loops, and the processes that link 
attachment style to caregiving are likely to be much more complex than those discussed and tested here. For example, attachment style may predict person-level factors (e.g., prosocial orientation), which predict relationship-level mediators (e.g., interdependence), which in turn predict motivations for caring for one's partner.

Another important goal for future research is to broaden the mediational model presented here to include the influence of the support recipient's characteristics and behavior in eliciting various forms of caregiving. For example, the level and type of social support one receives may be due, in part, to the support seeker's ability to clearly communicate his or her attachment needs and to make use of the support available to him or her (Blain, Thompson, \& Whiffen, 1993; Collins \& Feeney, 2000). Because the caregiving role is not exclusively assigned to one member of the dyad in adult relationships, responsive caregiving is likely to involve a balancing act to some degree. That is, both partners must encourage autonomy (provide a secure base) while also accepting dependence (provide a safe haven) when it is needed. This delicate balance of dependence and autonomy seems vital for healthy relationship functioning and may be a process that is negotiated by couple members over time. The longitudinal examination of the development and maintenance of this balance may help us to address important research questions such as the following: How much caregiving is too much or too little? At what point does caregiving become compulsive? Is it beneficial or harmful to provide support in the absence of need? Do people learn how to become better caregivers over time (as a result of the negotiation of this balance)? Do people exhibit the same caregiving patterns with respect to all significant people in their lives?

In conclusion, the purpose of this study was to shed light on caregiving processes in adult intimate relationships in an effort to gain insight into the functioning of the caregiving system. Aside from recent work by George and Solomon (1996, 1999), which presents a behavioral-systems framework for conceptualizing and studying the caregiving of mothers toward their children, in-depth investigations into the organization and functioning of the caregiving system in adulthood have been noticeably lacking. Because sensitive and responsive caregiving is essential not only for personal health and well-being but also for the development and maintenance of healthy and satisfying intimate relationships, we hope that the current investigation will provide a point of departure for future research examining the microdynamics of caregiving processes and the functioning of the caregiving system in adulthood.

\section{References}

Acitelli, L. K. (1996). The neglected links between marital support and marital satisfaction. In G. R. Pierce, B. R. Sarason, \& I. G. Sarason (Eds.), Handbook of social support and the family (pp. 83-103). New York: Plenum Press.

Ainsworth, M. D. S., Blehar, M. C., Waters, E., \& Wall, S. (1978). Patterns of attachment: Psychological study of the strange situation. Hillsdale, NJ: Erlbaum.

Ainsworth, M. D. S., \& Eichberg, C. (1991). Effects on infant-mother attachment of mother's unresolved loss of an attachment figure, or other traumatic experience. In C. M. Parkes, J. Stevenson-Hinde, \& P. Marris (Eds.), Attachment across the life-cycle (pp. 160-186). London: Routledge.

Arbuckle, J. L. (1997). Amos users' guide version 3.6. Chicago: SmallWaters Corporation.
Aron, A., Aron, E. N., \& Smollan, D. (1992). Inclusion of other in the Self Scale and the structure of interpersonal closeness. Journal of Personality and Social Psychology, 63, 596-612.

Baldwin, M. W., \& Sinclair, L. (1996). Self-esteem and "if ... then" contingencies of interpersonal acceptance. Journal of Personality and Social Psychology, 71, 1130-1141.

Baron, R. M., \& Kenny, D. A. (1986). The moderator-mediator distinction in social psychological research: Conceptual, strategic, and statistical considerations. Journal of Personality and Social Psychology, 51, 11731182.

Bartholomew, K., \& Horowitz, L. M. (1991). Attachment styles among young adults: A test of a four-category model. Journal of Personality and Social Psychology, 61, 226-244.

Batson, C. D., Batson, J. G., Slingsby, J. K., Harrell, K. L., Peekna, H. M., \& Todd, R. M. (1991). Empathic joy and the empathy-altruism hypothesis. Journal of Personality and Social Psychology, 61, 413-426.

Batson, C. D., O'Quin, K., Fultz, J., Vanderplas, M., \& Isen, A. (1983). Influence of self-reported distress and empathy on egoistic versus altruistic motivation to help. Journal of Personality and Social Psychology, 45, 706-718.

Benoit, D., \& Parker, K. C. H. (1994). Stability and transmission of attachment across three generations. Child Development, 65, 14441456.

Bentler, P. M. (1990). Comparative fit indexes in structural models. Psychological Bulletin, 107, 238-246.

Berscheid, E., Snyder, M., \& Omoto, A. M. (1989). The relationship closeness inventory: Assessing the closeness of interpersonal relationships. Journal of Personality and Social Psychology, 57, 792-807.

Blain, M. D., Thompson, J. M., \& Whiffen, V. E. (1993). Attachment and perceived social support in adolescence: The interaction between working models of self and others. Journal of Adolescent Research, 8 , 226-241.

Bowlby, J. (1973). Attachment and loss: Separation, anxiety and anger. New York: Basic Books.

Bowlby, J. (1980). Attachment and loss: Sadness and depression. New York: Basic Books.

Bowlby, J. (1982). Attachment and loss: Attachment. New York: Basic Books.

Bowlby, J. (1988). A secure base. New York: Basic Books.

Brennan, K. A., Clark, C. L., \& Shaver, P. R. (1998). Self-report measurement of adult attachment: An integrative overview. In J. A. Simpson \& W. S. Rholes (Eds.), Attachment theory and close relationships (pp. 46-76). New York: Guilford Press.

Bretherton, I. (1987). New perspectives on attachment relations: Security, communication, and internal working models. In J. D. Osofsky (Ed.), Handbook of infant development (2nd ed.; pp. 1061-1100). New York: Wiley.

Carnelley, K. B., Pietromonaco, P. R., \& Jaffe, K. (1996). Attachment, caregiving, and relationship functioning in couples: Effects of self and partner. Personal Relationships, 3, 257-278.

Cassidy, J. (1994). Emotion regulation: Influences of attachment relationships. Monographs of the Society for Research in Child Development, 59 (2-3, Serial No. 240), 228-249.

Cassidy, J. (2000). Truth, lies, and intimacy: An attachment perspective. Manuscript submitted for publication.

Cassidy, J., \& Berlin, L. J. (1994). The insecure/ambivalent pattern of attachment: Theory and research. Child Development, 65, 971-991.

Cialdini, R. B., Schaller, M., Houlihan, D., Arps, K., Fultz, J., \& Beaman, A. L. (1987). Empathy-based helping: Is it selflessly or selfishly motivated? Journal of Personality and Social Psychology, 52, 749-758.

Clark, M. S., Fitness, J., \& Brissette, I. (2000). Understanding people's perceptions of relationships is crucial to understanding their emotional lives. In G. Fletcher \& M. S. Clark (Eds.), Blackwell handbook of social 
psychology: Interpersonal processes (pp. 253-278). Oxford, England: Blackwell.

Clark, M. S., Mills, J., \& Powell, M. C. (1986). Keeping track of needs in communal and exchange relationships. Joumal of Personality and Social Psychology, 51, 333-338.

Clark, M. S., Ouellette, R., Powell, M. C., \& Milberg, S. (1987). Recipient's mood, relationship type, and helping. Journal of Personality and Social Psychology, 53, 94-103.

Collins, N. L., \& Feeney, B. C. (2000). A safe haven: An attachment theory perspective on support-seeking and caregiving in adult romantic rela tionships. Journal of Personality and Social Psychology, 78, 1053-1073.

Collins, N. L., \& Read, S. J. (1990). Adult attachment, working models, and relationship quality in dating couples. Journal of Personality and Social Psychology, 58, 644-663.

Crowell, J. A., \& Feldman, S. S. (1988). Mothers' internal models of relationships and children's behavioral and developmental status: A study of mother-child interaction. Child Development, 59, 1273-1285.

Crowell, J. A., \& Feldman, S. S. (1991). Mothers' working models of attachment relationships and mother and child behavior during separation and reunion. Developmental Psychology, 27, 597-605.

Cutrona, C. E. (1996). Social support as a determinant of marital quality: The interplay of negative and supportive behaviors. In G. R. Pierce, B. R. Sarason, \& I. G. Sarason (Eds.), Handbook of social support and the family (pp. 173-194). New York: Plenum Press.

Cutrona, C. E., \& Russell, D. (1990). Type of social support and specific stress: Toward a theory of optimal matching. In I. G. Sarason, B. R. Sarason, \& G. R. Pierce (Eds.), Social support: An interactional view (pp. 319-366). New York: Wiley.

Dakof, G. A., \& Taylor, S. E. (1990). Victims' perceptions of social support: What is helpful from whom? Journal of Personality and Social Psychology, 58, 80-89.

Davis, M. H. (1983). Measuring individual differences in empathy: Evidence for a multidimensional approach. Journal of Personality and Social Psychology, 44, 113-126.

Dovidio, J. F., Allen, J. L., \& Schroeder, D. A. (1990). The specificity of empathy-induced helping: Evidence for altruistic motivation. Journal of Personality and Social Psychology, 59, 249-260.

Dunning, D., \& Hayes, A. F. (1996). Evidence for egocentric comparison in social judgment. Journal of Personality and Social Psychology, 71, 213-229.

Eysenck, S. B., \& Eysenck, H. J. (1978). Impulsiveness and venturesomeness: Their position in a dimensional system of personality description. Psychological Reports, 43, 1247-1255.

Feeney, B. C., \& Collins, N. L. (1998, June). An attachment/caregiving perspective on social support exchanges in intimate relationships. Paper presented at the Ninth International Conference on Personal Relationships, Saratoga Springs, NY

Feeney, J. A. (1996). Attachment, caregiving, and marital satisfaction. Personal Relationships, 3, 401-416.

Feeney, J. A., \& Noller, P. (1990). Attachment style as a predictor of adult romantic relationships. Journal of Personality and Social Psychology, $58,281-291$

Fraley, R. C., Davis, K. E., \& Shaver, P. R. (1998). Dismissing-avoidance and the defensive organization of emotion, cognition, and behavior. In J. A. Simpson \& W. S. Rholes (Eds.), Attachment theory and close relationships (pp. 249-279). New York: Guilford Press.

Fraley, R. C., Garner, J. P., \& Shaver, P. R. (2000). Adult attachment and the defensive regulation of attention and memory: Examining the role of preemptive and postemptive defensive processes. Journal of Personality and Social Psychology, 79, 1-11.

Fraley, R. C., \& Shaver, P. R. (1997). Adult attachment and the suppression of unwanted thoughts. Journal of Personality and Social Psychology, 73, 1080-1091.

Fraley, R. C., \& Shaver, P. R. (1998). Airport separations: A naturalistic study of adult attachment dynamics in separating couples. Journal of Personality and Social Psychology, 75, 1198-1212.

Fraley, R. C., \& Waller, N. G. (1998). Adult attachment patterns: A test of the typological model. In J. A. Simpson \& S. Rholes (Eds.), Attachment theory and close relationships (pp. 77-114). New York: Guilford.

George, C., \& Solomon, J. (1996). Representational models of relationships: Links between caregiving and attachment. Infant Mental Health Journal, 17, 198-216.

George, C., \& Solomon, J. (1999). Attachment and caregiving: The caregiving behavioral system. In J. Cassidy \& P. R. Shaver (Eds.), Handbook of attachment: Theory, research, and clinical applications (pp. 649670). New York: Guilford Press.

Hazan, C., \& Shaver, P. R. (1987). Romantic love conceptualized as an attachment process. Journal of Personality and Social Psychology, 52, 511-524.

Holmes, J. G. (1991). Trust and the appraisal process in close relationships. In W. H. Jones \& D. Perlman (Eds.), Advances in personal relationships: A research annual (Vol. 2; pp. 57-104). London: Jessica Kingsley.

Hu, L. \& Bentler, P. M. (1999). Cutoff criteria for fit indexes in covariance structure analysis: Conventional criteria versus new alternatives. Structural Equation Modeling, 6, 1-55.

Johnson, R., Hobfoll, S. E., \& Zalcberg-Linetzy, A. (1993). Social support knowledge and behavior and relational intimacy: A dyadic study. Journal of Family Psychology, 6, 266-277.

Julien, D., \& Markman, H. J. (1991). Social support and social networks as determinants of individual and marital outcomes. Journal of Social and Personal Relationships, 8, 549-568.

Kline, R. B. (1998). Principles and practice of structural equation modeling. New York: Guilford.

Kobak, R. R., \& Sceery, A. (1988). Attachment in late adolescence: Working models, affect regulation, and perception of self and others. Child Development, 59, 135-146.

Kunce, L. J., \& Shaver, P. R. (1994). An attachment-theoretical approach to caregiving in romantic relationships. In $\mathrm{K}$. Bartholomew \& D. Perlman (Eds.), Advances in personal relationships (Vol. 5, pp. 205-237). London: Jessica Kingsley.

Main, M., Kaplan, N., \& Cassidy, J. (1985). Security in infancy, childhood, and adulthood: A move to the level of representation. Monographs of the Society for Research in Child Development, 50 (1-2, Serial No. 209), 66-104.

McGraw, K. O., \& Wong, S. P. (1996). Forming inferences about some intraclass correlation coefficients. Psychological Methods, 1, 30-46.

Mills, J., \& Clark, M. S. (1994). Communal and exchange relationships: Controversies and research. In R. Erber \& R. Gilmour (Eds.), Theoretical frameworks for personal relationships (pp. 29-42). Hillsdale, $\mathrm{NJ}$ : Erlbaum.

Mullen, B., Atkins, J. L., Champion, D. S., Edwards, C., Hardy, D., Story, J. E., \& Vanderkloc, M. (1985). The false consensus effect: A metaanalysis of 115 hypothesis tests. Journal of Experimental Social Psy. chology, 21, 262-283.

Nunally, J. C., \& Bernstein, I. H. (1994). Psychometric theory (3rd ed.). New York: McGraw-Hill.

Ognibene, T. C., \& Collins, N. L. (1998). Adult attachment styles, perceived social support, and coping strategies. Journal of Social and Personal Relationships, 15, 323-345.

Pierce, G. R., Sarason, I. G., \& Sarason, B. R. (1991). General and relationship-based perceptions of social support: Are two constructs better than one? Journal of Personality and Social Psychology, 6I, 1028-1039.

Rempel, J. K., Holmes, J. G., \& Zanna, M. P. (1985). Trust in close relationships. Journal of Personality and Social Psychology, 49, 95-1 12.

Rholes, W. S., Simpson, J. A., \& Orina, M. M. (1999). Attachment and 
anger in an anxiety-provoking situation. Journal of Personality and Social Psychology, 76, 940-957.

Rusbult, C. E. (1983). A longitudinal test of the investment model: The development (and deterioration) of satisfaction and commitment in heterosexual involvements. Journal of Personality and Social Psychology, 45, 5101-5117.

Rusbult, C. E., \& Buunk, B. P. (1993). Commitment processes in close relationships: An interdependence analysis. Journal of Social and Personal Relationships, 10, 175-204.

Salovey. P. (1992). Mood-induced self-focused attention. Journal of Personality and Social Psychology, 62, 699-707.

Simpson, J. A. (1990). Influence of attachment styles on romantic relationships. Journal of Personality and Social Psychology, 59, 971-980.

Simpson. J. A., Rholes, W. S., \& Nelligan. J. S. (1992). Support seeking and support giving within couples in an anxiety-provoking situation: The role of attachment styles. Journal of Personality and Social Psychology, $62,434-446$.

Solomon, J., \& George, C. (1996). Defining the caregiving system: Toward a theory of caregiving. Infant Mental Health Journal, 17. 183-197.

Thornton, S., \& Thornton, D. (1995). Facets of empathy. Personality and Individual Differences, 19, 765-767.

van IJzendoorn, M. H. (1995). Adult attachment representations, parental responsiveness, and infant attachment: A meta-analysis on the predictive validity of the Adult Attachment Interview. Psychological Bulletin. 117. 387-403.

Van Lange, P. A. M., Rusbult, C. E., Drigotas, S. M.. Arriaga, X. B., Witcher, B. S., \& Cox, C. L. (1997). Willingness to sacrifice in close relationships. Journal of Personality and Social Psychology, 72, 13731395.

Vinokur, A. D.. Price, R. H., \& Caplan. R. D. (1996). Hard times and hurtful partners: How financial strain affects depression and relationship satisfaction of unemployed persons and their spouses. Journal of Personality and Social Psychology, 71, 166-179.

Wegner, D. M., \& Giuliano, T. (1980). Arousal-induced attention to self. Journal of Personality and Social Psychology, 38, 719-726.

Weiss, R. L. (1980). Strategic behavioral marital therapy: Toward a model for assessment and intervention. In J. P. Vincent (Ed.). Advances in family intervention, assessment and theory (Vol. 1, pp. 229-271). Greenwich, CT: JAI Press.

Wood, J. V., Saltzberg, J. A., \& Goldsamt, L. A. (1990). Does affect induce self-focused attention? Journal of Personality and Social Psychology: $58,899-908$.

Received June 12, 2000

Revision received January 3, 2001

Accepted January 3, 2001

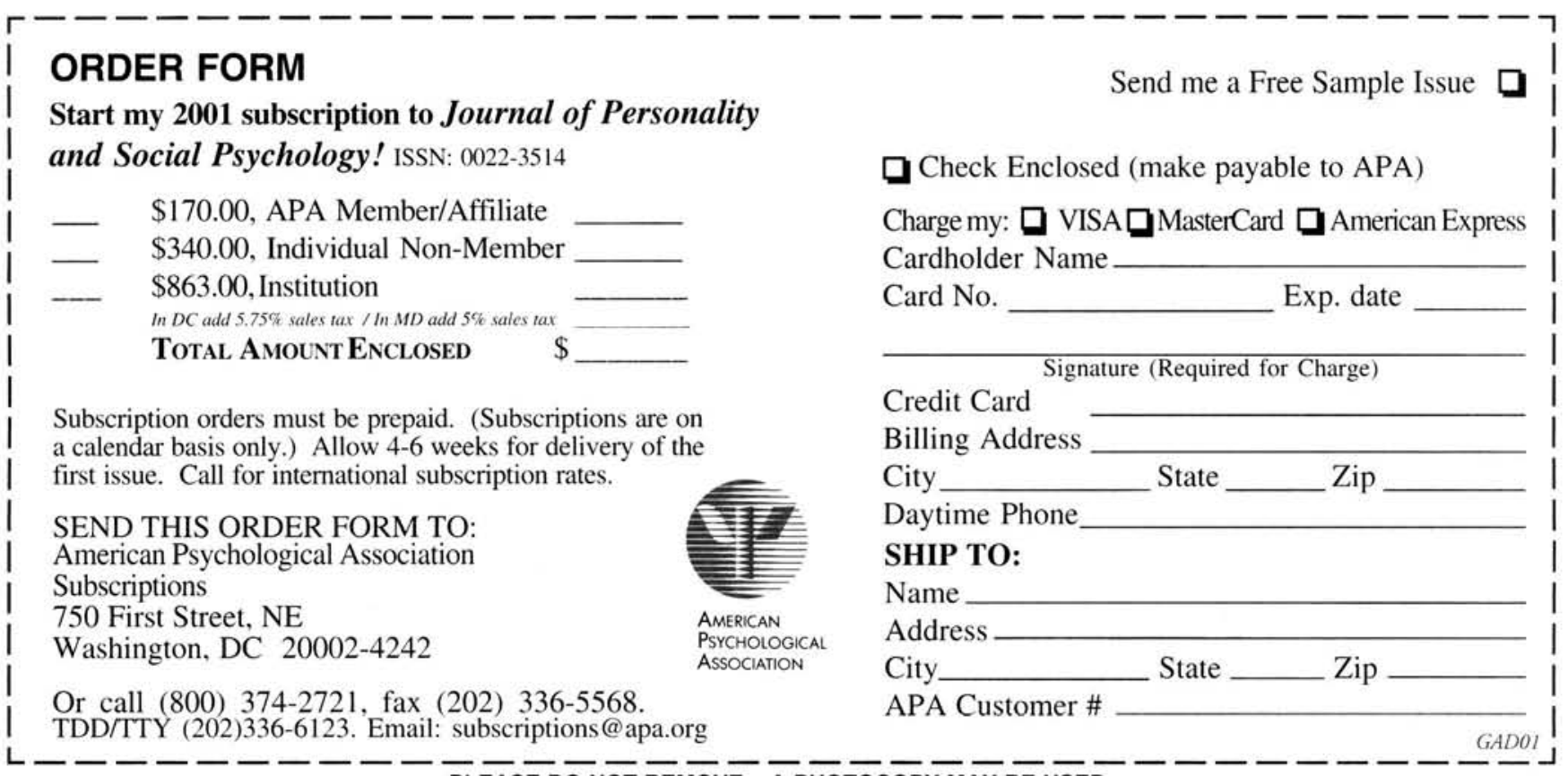

